\title{
Nanotechnology advances in pathogen- and host-targeted antiviral delivery: multipronged therapeutic intervention for pandemic control
}

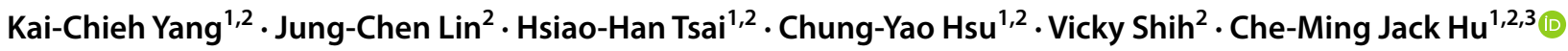

Accepted: 11 March 2021 / Published online: 21 March 2021

(c) Controlled Release Society 2021

\begin{abstract}
The COVID-19 pandemic's high mortality rate and severe socioeconomic impact serve as a reminder of the urgent need for effective countermeasures against viral pandemic threats. In particular, effective antiviral therapeutics capable of stopping infections in its tracks is critical to reducing infection fatality rate and healthcare burden. With the field of drug delivery witnessing tremendous advancement in the last two decades owing to a panoply of nanotechnology advances, the present review summarizes and expounds on the research and development of therapeutic nanoformulations against various infectious viral pathogens, including HIV, influenza, and coronaviruses. Specifically, nanotechnology advances towards improving pathogen- and host-targeted antiviral drug delivery are reviewed, and the prospect of achieving effective viral eradication, broad-spectrum antiviral effect, and resisting viral mutations are discussed. As several COVID-19 antiviral clinical trials are met with lackluster treatment efficacy, nanocarrier strategies aimed at improving drug pharmacokinetics, biodistributions, and synergism are expected to not only contribute to the current disease treatment efforts but also expand the antiviral arsenal against other emerging viral diseases.
\end{abstract}

Keywords Nanoparticles · Antivirals $\cdot$ Drug delivery $\cdot$ COVID-19 $\cdot$ Host-targeted antiviral $\cdot$ Antiviral state $\cdot$ Nanosponge $\cdot$ Nanodecoy

\section{Introduction}

Infectious viral diseases present a major public health threat that prompts continuing developmental efforts for effective antivirals. Until today, more than 6590 virus species had been classified [1], more than 1031 viruses on Earth were estimated [2], yet only 50 antiviral drugs have been approved for human use [3]. In 2020, severe acute respiratory syndrome coronavirus (SARS-CoV-2), which was first identified in Wuhan, China, led to a global pandemic that heightens the urgency to search for effective antiviral treatments. As of December $7^{\text {th }}, 2020$, the virus has led to 67 million

Che-Ming Jack Hu

chu@ibms.sinica.edu.tw

1 Taiwan International Graduate Program in Molecular Medicine, National Yang Ming Chiao Tung University and Academia Sinica, Taipei 112304, Taiwan

2 Institute of Biomedical Sciences, Academia Sinica, Taipei 115201, Taiwan

3 Center of Applied Nanomedicine, National Cheng Kung University, Tainan 704017, Taiwan cases and more than 1.5 million deaths reported globally [4]. The recent interim results from the Solidarity Trial, which is an international clinical trial enrolling patients in over 30 countries aimed at finding an effective treatment for COVID19 , paint a sobering picture of the antiviral landscape for COVID-19 treatment. Four antiviral compounds, including remdesivir, hydroxychloroquine, iopinavir/ritonavir, and interferon, reportedly showed little or no effect on patient prognosis in the trial [5]. The quest for effective antivirals is not unique to the COVID-19 pandemic and has been an ongoing challenge in the continuing battle against numerous, mutation-prone viral pathogens. Early in the 1960s, antiviral drugs were first designed to target viral proteins to interfere with their ability to highjack cellular machinery for replication. Amantadine and rimantadine, for example, served as antiviral drugs for influenza A that inhibit virus replication by impairing membrane protein $\mathrm{M} 2$, an acid-activated ion channel presented only on the surface of the influenza A viruses [6]. Unfortunately, the virus's rapid mutation soon led to widespread resistance; amantadine is no longer recommended due to drug resistance. Along with viruses' capability to evolve, new treatment modalities and 
pharmaceutical agents have emerged as researchers tap into other molecular pathways of virus replication. More recently, the emergence and advances of material science and nanotechnology research have added new design elements and creative freedom in antiviral formulation development, and the adoption of nanocarriers has shown significant promise in addressing the shortcomings of small molecule antiviral compounds. The present review summarizes the landscape of nanotechnology advances in antiviral drug delivery and discusses how emerging nanoformulation designs may be relevant in the COVID-19 pandemic.

The adoption of nanotechnology for numerous aspects of disease management, including pathogen detection, sanitization, treatment, and vaccination, has been covered in several recent reviews and commentaries [7-11]. Most notable among nanotechnology's contributions to pandemic control is the rapid rollout of mRNA vaccines made possible by nanocarriers comprised of ionizable lipids [12]. The present article focuses on the drug delivery benefit of nanocarriers for enhancing antiviral efficacy. We highlight different categories of antivirals and the design principles tailored to different antiviral compounds. Specifically, nanoparticle-based delivery strategies for enhancing pathogen- and host-targeted antivirals are reviewed. In addition, we present recent development in biomimetic nanocarriers and discuss their prospects towards targeted drug delivery to viral pathogens and virus-infected cells. While few antiviral nanoformulations have been developed against SARS-CoV-2, many nanocarrier design principles are readily compatible with the current treatment concepts against the pandemic.
The relevance of these nanocarrier delivery strategies to the COVID-19 pandemic is further discussed.

\section{Virus replication cycle and antiviral delivery}

Viruses rely on host cell machineries for replication, and the underlying mechanisms through which viruses invade, hijack, and release from a cell constitute drug targets where pharmaceutical interventions can intercept viral replications. Viral replication consists of multiple distinctive steps, including attachment, entry, uncoating, transcription/mRNA production, synthesis of viral components, virion assembly, and release, and many pathogen-targeted antivirals have been developed to intercept each of these steps (Fig. 1). To gain access to cellular machineries, viruses infect host cells by interacting with the surface marker on cellular membranes and then fusing with the cellular membranes [13]. The putative interaction between SARS-CoV-2 and human ACE2, for instance, has led to blocking strategies based on ACE2 mimics as well as monoclonal and polyclonal antibodies against SARS-CoV-2 spike proteins [14]. A current anti-HIV drug, Enfuvirtide, is an HIV fusion inhibitor that also targets this step. It works by targeting the final stage of fusion, preventing the entry of HIV and protecting uninfected cells from being infected. After the virus enters the host cell, it releases its genome by uncoating, a process in which viral capsid is removed via enzyme degradation or simple dissociation [15], leading to viral release of genomic nucleic acid, which can either be DNA or RNA. The virus genome replication and the translation of viral proteins subsequently take place, leading to the production of viral protein

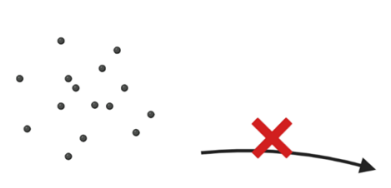

Challenges in antiviral drug delivery:

- Poor cellular uptake

- Poor pharmacokinetics

- Off-targeting effect

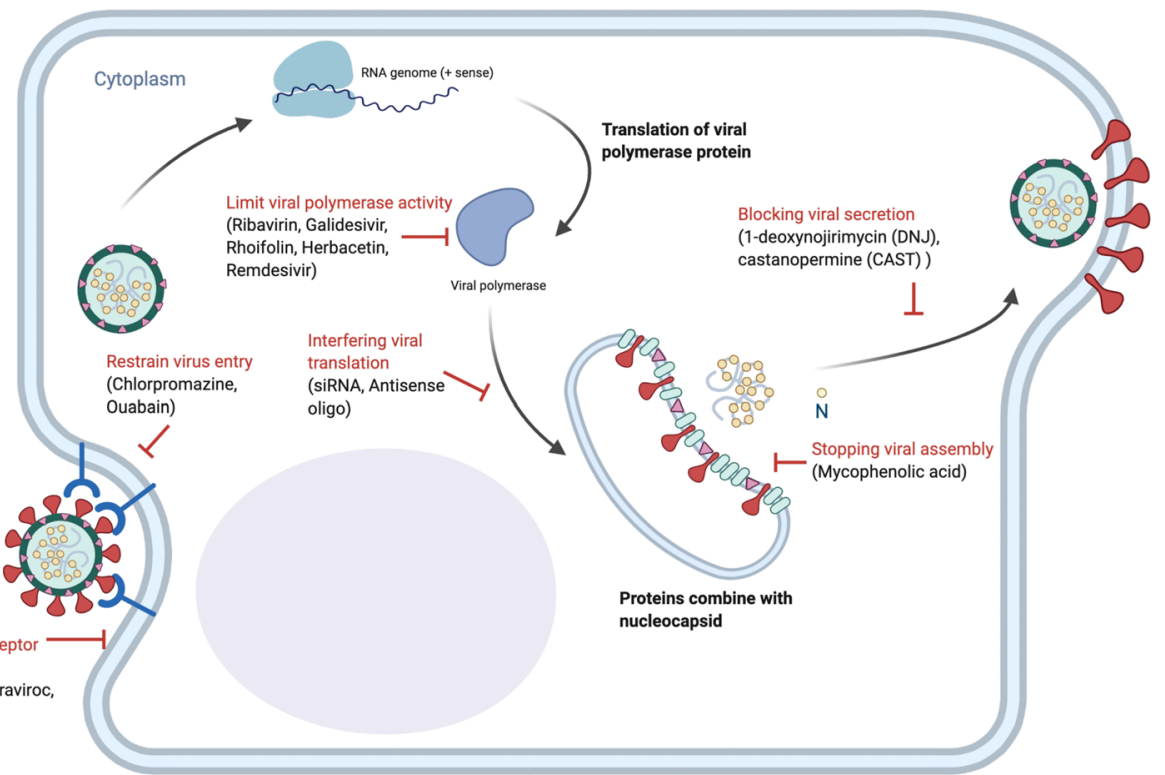

Fig. 1 A schematic representation of virus replication step, antiviral drugs aimed at distinctive stages of viral replication, and gain of feature with nanocarriers. Created with BioRender 
components, including its shell, envelope, capsids, and nucleoproteins. In the case of SARS-CoV-2, a critical step in the viral replication lies in the translation of RNA-dependent RNA polymerase (RdRp), which replicates viral RNA for viral protein synthesis [16]. The use of remdesivir, which is a nucleoside mimic, functions by blocking RdRp during mRNA replication, thereby halting virus proliferation[17]. Ribavirin, another antiviral drug primarily used to treat hepatitis $\mathrm{C}$ and respiratory syncytial virus (RSV), also functions as a nucleoside inhibitor and stops viral mRNA synthesis and viral mRNA capping. Upon successful translation of viral RNA into viral proteins, structural-mediated self-assembly of the virus particles leads to complete production of the virus. The virus can then be released from the host cell via cell lysis [18]. Compounds that interfere with post-translational modification of proteins, such as glycosylation, can be applied to intercept this last stage of viral replication. For instance, 1-deoxynojirimycin (DNJ), an alpha-glucosidase inhibitor, can block hepatitis B virus (HBV) secretion by interfering with viral protein glycosylation [19]. Figure 1 illustrates the different antiviral drugs aimed at targeting individual steps of viral replication, and it shows the delivery barriers facing antiviral compounds. Outside of antivirals that blocks host-pathogen interactions, all other antiviral compounds require entry into the cytosolic compartment for their intended actions. Take remdesivir for example, the active, nucleotide analog component cannot pass through the plasma membrane barrier, and an enzyme-labile proTide linker is required to deliver these nucleotide analogs [20]. The same design can be found in other nucleotide-based antivirals such as sofosbuvir, tenofovir, and alafenamide. While the delivery challenge of nucleotide analogs has been addressed with prodrug chemistry, it highlights the delivery barriers, including low cellular uptake, poor pharmacokinetics, and the off-target effect, which can impede the development of small molecule and macromolecular antiviral compounds. With the goal of more effectively shuttling antiviral compounds to cells and tissues, it can be conceived that nanocarriers, a platform that shares structural and size similarity with natural virions, can be utilized to direct drug payloads to sites preferentially accessed by viruses. Other benefits of nanocarrers, such as sustained drug release, multidrug synchronization, and targeting funcitonalization, can further broaden the landscape of antiviral designs and addresses the shortcomings of antiviral compounds through specifically designed controlled release.

\section{Nanoparticles delivering pathogen-targeted antivirals}

While many approved antivirals exhibit excellent efficacy in containing viral diseases such as HIV, influenza, and hepatitis $\mathrm{C}$, ongoing concerns with virus mutations, emerging viral threats, as well as the need to improve patient compliance and treatment logistics necessitates continuing development of antiviral formulations [21]. As nanocarrier platforms emerge in the last few decades, nanoparticles are now widely used in many treatment applications, such as cancer immunotherapy, antimicrobial, bioimaging, and diagnosisrelated applications [22, 23]. As viruses are nanoparticulates by nature, the inherent morphological similarity shared by synthetic nanocarriers can help address the delivery barriers in antiviral treatment. For example, due to the morphological and size similarity, nanoparticles can be designed to be promptly uptaken by the cells, much like the virus delivering its genetic materials into the host cells. Alternation of a drug's pharmacokinetics and biodistributions can be specifically engineered to better direct antiviral compounds to infection [24].

With the technological progression of nanotechnology, including the introduction of a wide range of biocompatible nanoparticle platforms such as polymer- and lipidbased nanocarriers, drug compounds with a wide variety of physicochemical properties can be readily formulated for better stability, bioavailability, pharmacokinetics, and [24]. Nanoparticle-based antivirals can inhibit the effects of viral infection in several ways, and Table 1 lists antiviral nanoformulations that have been developed against major types of viral infections as categorized by pathogens. With several prior reviews having examined the different materials used for antiviral nanoparticle preparation [21, 25], we herein examine the different drug delivery modalities made possible by antiviral nanocarriers. For pathogen-targeted antivirals, common delivery motifs include long-acting antiviral nanoparticles, cell and tissue-targeted antiviral nanoparticles, combinational antiviral nanoparticles, and nucleic acid-based antiviral nanoparticles (Fig. 2). These four delivery motifs highlight two primary design principles in antiviral nanoformulations: (1) modifying pharmacokinetics and biodistributions and (2) enabling complex antiviral payload designs.

\section{Long-acting antiviral nanoparticles}

Most antiviral formulations are administered within a short time period to suppress the acute onset of viral infections. In some cases of chronic infections, such as in the case of HIV, antiviral intake over a prolonged period is needed for sustained virus control. Although current antiviral drugs have significantly reduced disease mortality and extended the lifetime for HIV-1-infected patients, patient compliance on lifelong drug dosing has become a notable limitation. In such cases, a long-acting antiviral formulation that can sustain the drugs' therapeutic concentrations in patients can be highly beneficial. For patients to achieve sustained viral suppression, the systemic antiviral concentration must be closely monitored and maintained at its therapeutic level. 
Table 1 A summary of nanocarriers developed for enhancing antiviral drug delivery

\begin{tabular}{|c|c|c|c|c|}
\hline Formulation & Virus type & Payload & Feature & Ref \\
\hline \multicolumn{5}{|l|}{ Long-acting } \\
\hline PLGA-chitosan & HIV & Tenofovir & $\begin{array}{l}\text { - Higher drug loading } \\
\text { - Sustain release }\end{array}$ & {$[26]$} \\
\hline $\begin{array}{l}\text { Poloxamer } 407(\mathrm{P} 407) \\
\text { Poloxamer } 188(\mathrm{P} 188)\end{array}$ & HIV & $\begin{array}{l}\text { Ritonavir-boosted } \\
\text { Atazanavir }\end{array}$ & $\begin{array}{l}\text { - Long-acting } \\
\text { - CD4+ restoration in blood } \\
\text { - Drug retention in recycling endosome }\end{array}$ & [27] \\
\hline PLGA & HIV & Emtricitabine (FTC) & $\begin{array}{l}\text { - High drug-loading for low cytotoxicity } \\
\text { - Sustained release } \\
\text { - In-cell retention }\end{array}$ & [28] \\
\hline PLGA & HIV & Bictegravir & $\begin{array}{l}\text { - Long-acting } \\
\text { - Prolonged intracellular retention } \\
\text { - Lower cytotoxicity } \\
\text { - Lower viral load }\end{array}$ & [29] \\
\hline $\begin{array}{l}\text { Liposome } \\
\text { DPPC/DPPG } \\
\text { DSPE-PEG-MAL }\end{array}$ & HIV & Indinavir & $\begin{array}{l}\text { - High drug conc. delivery } \\
\text { - Better HIV inhibition } \\
\text { - Low toxicity }\end{array}$ & {$[30]$} \\
\hline PLGA & HIV & Nelfinavir mesylate (NFV) & $\begin{array}{l}\text { - Increase drug solubility and oral bioavailability } \\
\text { - Sustained release }\end{array}$ & {$[31]$} \\
\hline PLGA & HBV & Lamivudine & $\begin{array}{l}\text { - Extended release } \\
\text { - Improved bioavailability }\end{array}$ & \\
\hline \multicolumn{5}{|l|}{ Cell/tissue targeting } \\
\hline Poly( $\varepsilon$-caprolactone) (PCL) & HIV & Dapivirine & $\begin{array}{l}\text { - Promote intracellular drug delivery } \\
\text { - Cell type selected } \\
\text { - Low cytotoxicity } \\
\text { - Anti-HIV efficacy }\end{array}$ & {$[32]$} \\
\hline PLGA & HIV & Elvitegravir & $\begin{array}{l}\text { - BBB penetration } \\
\text { - Suppress HIV replication } \\
\text { - Better drug efficacy }\end{array}$ & {$[33]$} \\
\hline Liposome & HIV & HIV-1 protease inhibitor & $\begin{array}{l}\text { - gp120 targeted } \\
\text { - Prolonged antiviral activity } \\
\text { - Facilitated uptake only by the infected cell }\end{array}$ & {$[34]$} \\
\hline PEG-PLGA & HIV & $\begin{array}{l}\text { - Histone deacetylase } \\
\text { inhibitor } \\
\text { - Suberoylanilide } \\
\text { hydroxamic acid (SAHA) } \\
\text { - Protease inhibitor nelfina- } \\
\text { vir }(\mathrm{Nel})\end{array}$ & $\begin{array}{l}\text { - CD45RO targeted (latenly CD4) } \\
\text { - Activate and inhibit latent virus }\end{array}$ & {$[35]$} \\
\hline Liposome & CMV & Ganciclovir & $\begin{array}{l}\text { - Intravitreal injection } \\
\text { - Better inhibitory for CMV } \\
\text { - Lower cytotoxicity } \\
\text { - Uptake by all Tf receptor cells }\end{array}$ & {$[36]$} \\
\hline Liposome & COVID-19 & Lactoferrin & $\begin{array}{l}\text { - Inhibit ROS generation } \\
\text { - Pulmonary targeted } \\
\text { - Decrease viral replication }\end{array}$ & NCT04475120 \\
\hline Inhaled nanoparticle & COVID-19 & Remdesivir & $\begin{array}{l}\text { - Pulmonary targeted } \\
\text { - Accessible administration } \\
\text { - Lower systemic toxicity }\end{array}$ & NCT04480333 \\
\hline \multicolumn{5}{|l|}{ Combinational } \\
\hline PLGA & HIV & $\begin{array}{l}\text { - Tenofovir alafenamide } \\
\text { - Elvitegravir } \\
\text { - Emtricitabine }\end{array}$ & $\begin{array}{l}\text { - Decrease viral load } \\
\text { - Slow, Sustain release } \\
\text { - Limited systemic clearance }\end{array}$ & {$[37]$} \\
\hline Lactoferrin nanoparticles & HIV & $\begin{array}{l}\text { - Zidovudine } \\
\text { - Efavirenz } \\
\text { - Lamivudine }\end{array}$ & $\begin{array}{l}\text { - High payload encapsulation } \\
\text { - Controlled release with low toxicity } \\
\text { - Improved in-vivo pharmacokinetic }\end{array}$ & {$[38]$} \\
\hline Lipid nanoparticles & HIV & $\begin{array}{l}\text { - Atazanvir } \\
\text { - Darunavir }\end{array}$ & $\begin{array}{l}\text { - } \mathrm{pH} \text {-responsive } \\
\text { - Sustain release }\end{array}$ & [39] \\
\hline
\end{tabular}


Table 1 (continued)

\begin{tabular}{|c|c|c|c|c|}
\hline Formulation & Virus type & Payload & Feature & Ref \\
\hline Lipid nanoparticles & HIV & $\begin{array}{l}\text { - Lopinavir } \\
\text { - Ritonavir } \\
\text { - Tenofovir }\end{array}$ & $\begin{array}{l}\text { - Higher intracellular conc } \\
\text { - Controlled release }\end{array}$ & [40] \\
\hline PEG-PLGA & IAV & $\begin{array}{l}\text { - Diphyllin } \\
\text { - Bafilomycin }\end{array}$ & $\begin{array}{l}\text { - Higher drug loading with systained release } \\
\text { - Lower cytotoxicity } \\
\text { - Greater antivial activity }\end{array}$ & [41] \\
\hline \multicolumn{5}{|l|}{ Nucleic acid delivery } \\
\hline Liposome & HIV & RNAi: CCR5 & $\begin{array}{l}\text { - Lymphocyte targeted } \\
\text { - Systemic delivery siRNA } \\
\text { - T-cell HIV resistance }\end{array}$ & [42] \\
\hline Liposome & EBV & RNAi: EBV & $\begin{array}{l}\text { - Specific EBV targeted } \\
\text { - Systemic delivery siRNA } \\
\text { - High protection rate }\end{array}$ & [43] \\
\hline Lipid nanoparticles & $\mathrm{HBV}$ & RNAi: HBV & $\begin{array}{l}\text { - Lower toxicity } \\
\text { - Significant decrease in HBsAg content }\end{array}$ & [44] \\
\hline DTC-Apo liposome & $\mathrm{HCV}$ & RNAi: HCV & $\begin{array}{l}\text { - Increase antiviral activity } \\
\text { - Longer working duration } \\
\text { - Fast-acting }\end{array}$ & [45] \\
\hline PLGA & HSV-2 & $\begin{array}{l}\text { RNAi: Necti } \\
\text { RNAi: UL29.2 }\end{array}$ & $\begin{array}{l}\text { - Lower toxicity } \\
\text { - Topical administration } \\
\text { - Against both viral and host cell }\end{array}$ & [46] \\
\hline
\end{tabular}

Poor patient compliance can cause an increased risk for treatment failure and transmission of drug-resistant viruses. As such, several types of nanoparticles that prolong the pharmacokinetics of anti-HIV drugs, including tenofovir nanoparticles [26], [27], emtricitabine nanoparticles, and bictegravir nanoparticles, have been developed [28, 29]. For instance, Nowacek et al. demonstrated the preparation of a nanoformulated antiretroviral therapy (NanoART) through high-pressure homogenization of crystalline drugs with numerous surfactants for sustained drug delivery [49]. The NanoART are $200 \mathrm{~nm}$ in size and are readily uptaken by monocyte-derived macrophages. NanoART enables controlled release over 2 weeks, and weekly injections of the nanoformulation in HIV-1-infected humanized mice reduced viral loads by more than 1000 -fold and protected CD4+ T cell populations from viral infection without any noticeable toxicities [50]. In another example, Hobson et al. formulated semi-solid prodrug nanoparticles (SSPNs) by emulsiontemplated freeze-drying with emtricitabine, a highly watersoluble nucleoside reverse transcriptase inhibitor. The SSPNs exhibit long-acting drug release and high bioactivation under physiological conditions [51]. More recently, Kulkarni et al. showed an innovative way of making cabotegravir (CAB), a recently developed integrase inhibitor for HIV treatment, into a poloxamer-coated lipophilic prodrug nanocarrier. Excitingly, this nanoformulation comes with controlled hydrolysis that extends CAB's plasma circulation by up to 1 year with a single intramuscular injection [47]. These examples demonstrate the utility of nanocarriers towards sustained maintenance of antiviral levels for durable virus suppression (Fig. 1a). While prolonged antiviral treatment is not presently pursued against SARS-CoV-2 as the virus is generally believed to be contained and eradicated upon patient recovery, several cases of viral relapse leading to recurring acute COVID-19 episodes have been reported [52]. These suspected cases of viral relapse point to the possibility of virus latency in some recovered patients, and a long-acting antiviral formulation may offer recourse in the case of persistent viral infections.

\section{Cell- and tissue-targeted antiviral nanoparticles}

Nanoparticle surface functionalization with targeting ligand is a widely employed strategy in anticancer drug delivery towards enhancing drug accumulation in tumors. As antiviral drugs can likewise benefit from improved drug delivery to virus-infected sites, targeted nanoparticles directed towards specific cells and tissues have been designed for antiviral drug delivery. For example, liposomes surfacefunctionalized with anti-gp120 antibodies have been prepared to deliver an HIV-1 protease inhibitor to target infected cells with gp120 expression [34]. In another example, PEGPLGA nanoparticles functionalized with anti-CD45 have been prepared to enhance antiviral delivery to CD4 T cells, resulting in robust antiviral responses [35]. To enhance antiviral delivery to the eye, which is a hard-to-reach tissue that can be susceptible to cytomegalovirus infection, Asasutjarit et al. developed a nanocarrier with transferrin modification for the delivery of ganciclovir (GCV). This design enables active liposome targeting to cells in the retina. The liposome 
Fig. 2 Pathogen-targeted nanoformulation classified into four categories, including A longacting Cabotegravir prodrug fatty acid esters (FAE) nanorod, adapted from [47] capable of year-long drug release; $\mathbf{B}$ tissue targeting poly( $\varepsilon$-caprolactone) (PCL) nanoparticles capable of multivalent cell targeting, adapted from [48]; C combinational anti-HIV PLGA nanoparticle integrating current standard of care ART therapy, adapted from [37]; and D RNAbased anti-Ebola lipid nanoparticle that has shown therapeutic efficacy in non-human primates, adapted from [43]
A

Long-Acting

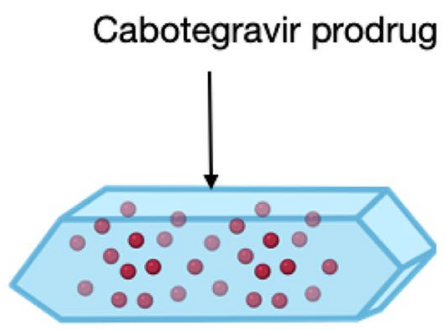

FAE Nanorod

Year long release

C

\section{Combinational}

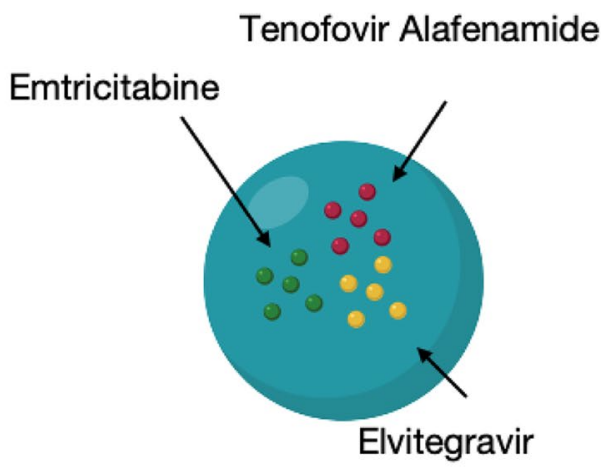

\section{B Cell/Tissue Targeting}

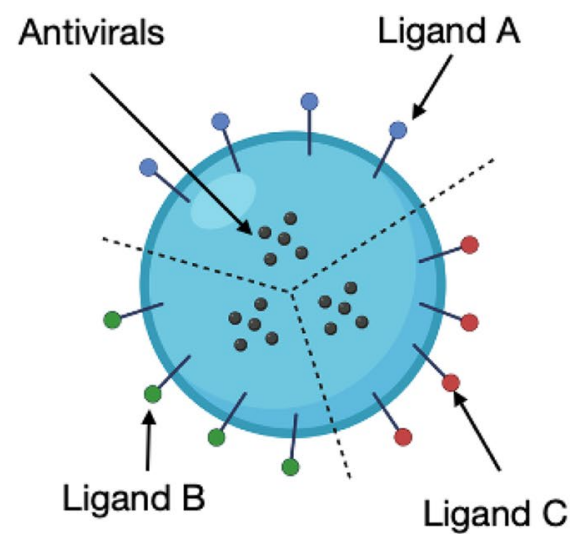

D

\section{Nucleic Acid Delivery}

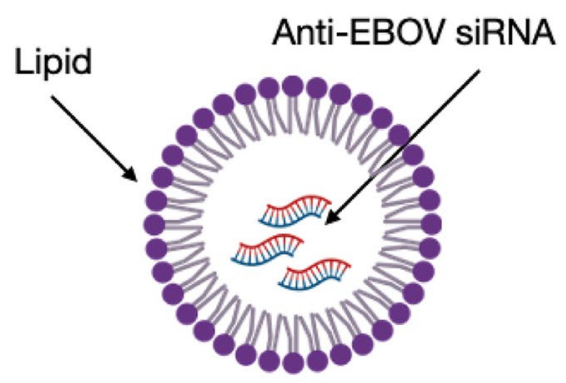

is capable of safely delivering antiviral to human retinal pigment epithelial cells with inhibitory effect against cytomegalovirus [36].

To tackle viruses capable of infecting multiple cell types, Neves et al. developed poly( $\varepsilon$-caprolactone) (PCL) nanoparticles encapsulating dapivirine, a non-nucleoside reverse transcriptase inhibitor for HIV treatment, with three different surface modifiers: poloxamer $338 \mathrm{NF}$ (PEO), sodium lauryl sulfate (SLS), and cetyltrimethylammonium bromide (CTAB) to maximize cellular uptake to Hela cells, VK2/E6E7 vaginal epithelial cells, and dendritic cells, respectively [32]. The PCL nanoparticles increased intracellular drug concentrations and improved antiviral activity with lower cytotoxicity over free dapivirine. In another example, Feng et al. exploited the interaction between high-density lipoprotein (HDL) and hepatocytes' surface receptors for antiviral delivery by complexing acyclovir palmitate with reconstituted HDL.
The delivery strategy presents a promising treatment approach for Hepatitis B virus (HBV) as the majority of the acyclovir palmitate complex gets delivered to the liver [53]. For respiratory infections induced by the likes of coronaviruses, it can be envisioned that lung-targeting strategies may enhance therapeutic antiviral treatments. In fact, several clinical trials are currently ongoing to examine the efficacy of inhalable anti-COVID-19 nanoformulations, including remdesivir nanoparticle and liposomal lactoferrin (Clinical Trial \#NCT04480333 and \#NCT04475120). These formulations and treatment regimens are designed to enhancing the tissue localization of active antiviral compounds. Among emerging drug delivery systems and strategies, unique carrier designs have also demonstrated enhanced pulmonary drug delivery via the intravenous route [54]. For instance, it has been recently shown that nanoparticle-loaded chemokines can be anchored onto red blood cells to enhance lung-targeted immunotherapy [55]. 
Such strategies may be similarly adapted to deliver antiviral compounds against pulmonary infections.

\section{Combinational antiviral nanoparticles}

Combinational antiviral formulations, or otherwise known as antiviral cocktails, are a widely adopted strategy to improve drug efficacy and to reduce the potential of drug resistance development among mutation-prone viruses. Amidst the COVID-19 pandemic, cocktail therapies involving antibodies, cytokines (i.e. interferon beta-1b), and small molecular compounds (i.e. lopinavir, ritonavir, and ribavirin) have been pursued extensively to treat infected patients $[56,57]$. The benefit of combinational antiviral is best exemplified in treatment against HIV. In the early 1990s, HIV treatments were predominantly monotherapies with limited effectiveness. As HIV mutates at a rapid pace, resistance against monotherapy treatment was frequently observed. A major clinical breakthrough came in the late 1990s as Ho et al. showed that the combination of three antiretroviral drugs targeting different stages of HIV replication was highly effective in suppressing HIV concentration in patient plasma [58, 59]. This breakthrough led to a paradigm shift in the design of antiviral regimens that favor combination therapy. Concurrently, nanoparticles provide the opportunity to deliver multiple drugs in controlled-release settings for higher safety and therapeutic profiles and the ability to reduce drug dosing schedule and complexity. As such, nanoformulations incorporating multiple antivirals have been designed to deliver multiple antiviral compounds for synergistic actions [39, 40]. Shibata et al. developed a PLGA nanoparticle to coencapsulate efavirenz (EFV), lopinavir (LPV), and ritonavir by a high-pressure homogenization method. The PLGA nanoparticle increases drug concentrations in several cellular compartments within HIV-1-infected H9 monocytic cells and leads to higher inhibition of the HIV-1 infection [60]. Kumar et al., on the other hand, prepared a lactoferrinfunctionalized nanocarrier containing zidovudine, efavirenz, and lamivudine to enhance drug efficacy and bioavailability; the nanoformulation was shown to reduce the toxicity of these first-line antiretrovirals [38]. Additionally, Mandal et al. co-delivered elvitegravir, tenofovir alafenamide, and emtricitabine with PLGA nanoparticles to treat chronic HIV-1 in a humanized mice model. After the mice received three subcutaneous doses of the nanoparticles, the viral load was decreased to a non-detectable level [37]. These studies highlight the utility of nanocarriers for synergizing multiple antiviral compounds through coordinated drug delivery.

\section{Nucleic acid-based antiviral nanoparticles}

The advancement of nucleic acid-based nanoformulation vastly expands the arsenal for pandemic management, and the benefits of nucleic acid-based formulations are best exemplified in the rapid clinical development of mRNAbased vaccines, which can be designed rapidly upon viral genome identification following a disease outbreak [61, 62]. Likewise, nucleic acid-based antivirals, such as those based on RNA interference (RNAi), may offer a similar advantage as such therapeutics can be quickly synthesized based on a virus' genetic information. RNAi antivirals rely on the intracellular delivery of small interfering RNA (siRNA), a 20-27 based pair double-stranded RNA, which forms RNA-induced silencing complex (RISC) to mediate the degradation of viral mRNA and prevent viral protein translation [63]. Numerous variants of nanoparticles have been introduced to overcome the delivery hurdle of siRNA [64], and several RNAi antivirals have been studied in various animal models. For example, during one of the most severe Ebola virus (EBOV) outbreaks between 2013 and 2016, Thi et al. prepared a lipid-based nanoparticle (LNP) that contains cocktail siRNA targeting conserved genetic sequences shared by multiple EBOV viral strains. The LNP treatment was able to protect non-human primates against lethal EBOV challenge, resulting in a decrease in viral load and organ viral spread compared with the control group [43]. RNAi-based nanoparticle treatments have also been adopted to reduce the expression of viral receptors on cells. Kim et al., for instance, formulated an anti-HIV treatment by encapsulating anti-CCR5 siRNA into liposome surface modified with lymphocyte function-associated antigen-1 (LFA-1), a specific ligand that can target $T$ cells and macrophages. The nanoformulation achieved leukocyte-specific gene silencing that was sustained for up to 10 days, and the reduction of CCR5 reduced HIV infectivity and decreased viral load in humanized mice [42]. Several other studies of RNAi-based antiviral nanoparticles have also shown promising preclinical efficacy against human simplex virus (HSV) [46], hepatitis B virus (HBV) [44], respiratory syncytial virus (RSV) [65], and influenza [66].

\section{Nanoparticles delivering host-targeted antivirals}

The antivirals covered in the previous section are primarily aimed at targeting specific pathogenic proteins or pathogenspecific infection mechanisms. Despite their wide adoption, pathogen-targeted antivirals generally possess narrowspectrum antiviral profiles and are susceptible to the emergence of drug resistance phenotypes, thereby presenting unmet needs in the management of viral diseases. For instance, as viral proteins are most likely structurally distinctive among different virus species, pathogen-targeted antivirals developed for prior viral outbreaks may not be useful for newly emerged viral pathogens. In addition, the selective 
pressure exerted by pathogen-targeted antivirals can favor drug resistance mutations. As such, host-targeted antivirals, which are compounds that target host proteins involved in the virus replication cycle, have emerged as promising alternatives towards broad-spectrum antiviral intervention. With the development of host-targeted antiviral compound being a fledging field that continues to introduce a growing number of chemical modulators against different infectious diseases [67], nanoparticle-based host-targeted antivirals have primarily focused on two specific mechanisms: inhibition of endosomal acidification and the induction of cellular antiviral state $[68,69]$. The ensuing section reviews nanoparticle antivirals based on these two treatment modalities.

\section{Antiviral nanoparticles targeting the host endosomal acidification process}

With many viruses expressing acid-labile membrane fusion proteins that rely on the acidifying environment of endosomes for cellular entry, inhibition of endosomal acidification is a promising strategy for broad-spectrum antiviral treatment and has shown effectiveness against HIV, flaviviruses [70], influenza virus, and coronaviruses [71-74]. Among antiviral agents aimed at inhibiting endosomal acidification and the ensuing virus entry into the cellular cytosol, chloroquine and its derivative, hydroxychloroquine, are perhaps the most publicized examples during the COVID-19 pandemic. The 70-year-old anti-malaria drug was among one of the earliest compounds being tested for COVID-19 treatment. Chloroquine and hydroxychloroquine function as weak bases from their buffering capacity inhibiting endolysosomal acidification upon localization in these acidifying organelles. Mechanistic studies have shown that chloroquine and hydroxychloroquine may not only inhibit host endosomal acidification but also reduce phosphatidylinositol binding clathrin assembly protein (PICALM) to decrease the rate of endocytosis and virus uptake [71, 75]. Although their unsatisfactory efficacy against COVID-19 in non-human primates and in large clinical trials have dampened enthusiasm on these compounds $[5,76]$, the drugs' good antiviral effect against several viruses as well as initial indications of anti-COVID-19 effectiveness in smaller clinical studies continues to inspire nanoformulation efforts towards improving the drug's delivery efficiency and effective dosage at the infection sites [77-79]. A potential reason behind the inadequate efficacy of chloroquine and hydroxychloroquine may be attributed to poor bioavailability and pulmonary delivery following oral administration [80]. As such, a liposomal formulation of hydroxychloroquine has been developed for pulmonary administration to enhance the drug's effective concentration in the lungs. As in vitro $\mathrm{EC}_{50}$ values of hydroxychloroquine against SARS-CoV-2 (0.72 to $17.3 \mathrm{uM}$ ) indicate that a high local concentration may be needed to halt viral replication, Tai et al. prepared a liposomal hydroxychloroquine formulation for pulmonary delivery [81]. Upon pharmacokinetic analysis in Sprague-Dawley rats following intratracheal administration, the liposomal formulation was found to enhance the drug's pulmonary exposure and half-life by 30 -fold and 2.5-fold, respectively, as compared with both intravenously and intratracheally administered free hydroxychloroquine. In addition to improving the drugs' pulmonary residence, the liposomal formulation reduced blood and cardiac exposure of the compounds, thereby improving its safety profile. The group has developed a nebulizer system to deliver the formulation for clinical translation. Although the benefit of liposome-formulated hydroxychloroquine is yet to be demonstrated against viral infections, a prior report of a liposomal chloroquine formulation showed improvement of the drug's anti-malaria effect via improved intracellular delivery [82]. In a mouse model of malaria infection, the nanoliposome formulation of chloroquine significantly reduced the degree of parasitemia. This study validates the principle of nanocarrier-mediated delivery toward enhancing the efficacy of endosomal acidification inhibitors for disease treatment (Fig. 3).

Aside from chloroquine and hydroxychloroquine, bafilomycin, diphyllin, and saliphenylhalamide (SaliPhe) have also received much scientific interest as broad-spectrum antiviral candidates that function via the inhibition of host endosomal acidification. As opposed to acting as weak bases, these compounds directly inhibit vacuolar-type ATPase (V-ATPase) to obviate its proton-pumping action from acidifying the endolysosomal compartment. Unlike the hydrophilic chloroquine and hydroxychloroquine, however, these V-ATPase inhibitors typically have poor solubility and thus have limited therapeutic efficacy, and nanocarriers provide a much-needed vehicle to solubilize these compounds for cellular delivery [41, 83]. Take SaliPhe for example, SaliPhe encapsulated by thermally hydrocarbonized porous silicon (THCPSi) nanoparticles increased dissolution of the drug, leading to inhibition of influenza A virus infection with lower cytotoxicity in vitro. In the case of diphyllin, another V-ATPase inhibitor extracted from the plant Cleistanthus collinus, broad-spectrum antiviral activity has been demonstrated against influenza virus, Zika virus, and coronaviruses [84-86]. To improve the solubility and safety profile of the compound, nanoparticulate diphyllin has been prepared using poly (ethylene glycol)-block-poly(lactideco-glycolide) (PEG-PLGA). In a study that examines the antiviral effect of diphyllin nanoparticle against feline infectious peritonitis virus (FIPV), a coronavirus infecting cats but with high similarity to SARS-CoV-2 in terms of pathogenesis and disease symptoms [87], diphyllin nanoparticles not only increased the antiviral activity over free diphyllin but reduced cellular cytotoxicity in an in vitro model [84]. In another study that examines the antiviral applicability of 
Fig. 3 A Schematic of endosome acidification inhibition for halting cytosolic entry of viruses. Nanoformulation in this category include $\mathbf{B}$ chloroquine nanoliposomes, adapted from [82] (copyright 2019 with permission from Elsevier), $\mathbf{C}$ silicon nanoparticles contains SaliPhe, adapted from [83], and D diphyllin encapsulated PEGPLGA nanoparticles, adapted from [41], copyright 2019 with permission from Dove Medical Press

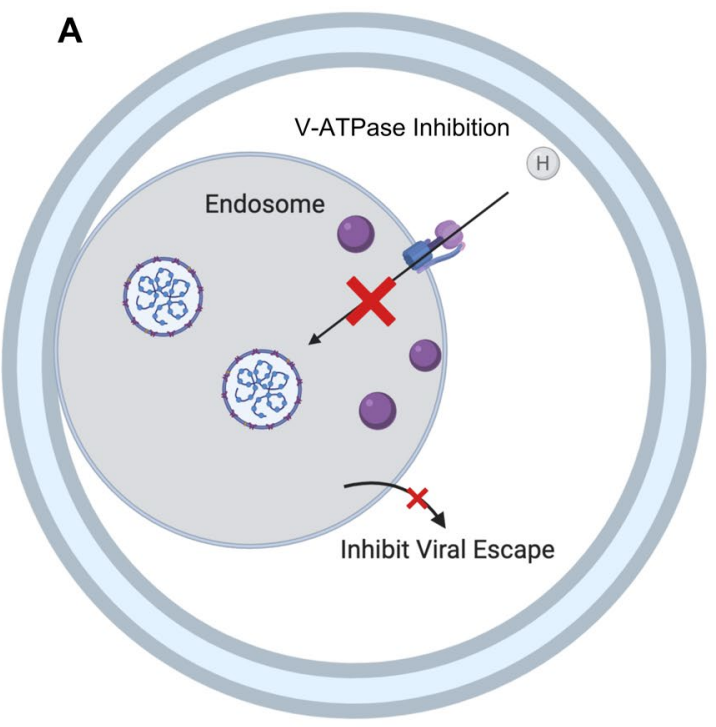

Endosome Acidification Inhibition
Endosome Acidification Inhibition

B

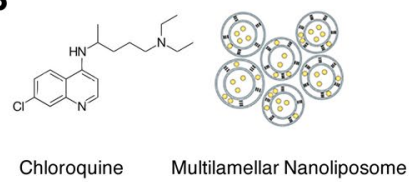

C
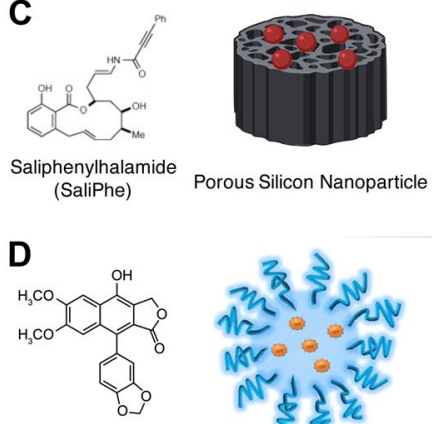

Diphyllin

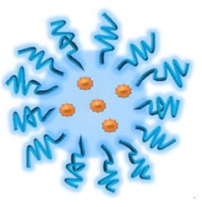

PEG-PLGA Nanoparticle diphyllin nanoparticles against influenza, a high-dose treatment of diphyllin nanoparticles was well tolerated in mice [41]. Significant survival advantage was conferred by the diphyllin nanoparticle treatment in mice challenged with lethal influenza infection, and in a nonlethal influenza challenge model, diphyllin nanoparticle treatment resulted in higher weight gain and reduced copies of viral RNA in the lungs. The enhanced therapeutic profile of diphyllin upon nanoparticle encapsulation can be explained by enhanced delivery of the V-ATPase inhibitor to the endolysosomal compartment of cells, enabling the released molecules to more effectively interact with their intended target. These studies highlight the utility of host-targeted antiviral nanocarriers as a broad-spectrum strategy against viral infections.

\section{Antiviral nanoparticles inducing cellular antiviral state}

Interferons (IFNs), and in particular type-I IFNs, are being actively pursued as therapeutic interventions against COVID-19 [5, 88], and multiple studies have linked COVID19 disease severity to reduced levels of endogenously produced IFNs $[89,90]$. IFNs, which can be produced by multiple cell types in the body, are widely expressed proinflammatory cytokines with potent antiviral and growth inhibitory effects. Recombinant protein engineering of IFNs has yielded clinically used biopharmaceuticals approved by the US Food and Drug Administration (FDA) for different antiviral and oncology treatments [91]. Endogenous in human bodies, IFNs can be induced by both viral and bacterial pathogens, which are sensed by several pattern recognition receptors (PRRs), including Toll-like receptors
(TLRs), a retinoic acid-inducible gene I (RIG-I)-like receptors (RLRs), nucleotide-binding and oligomerization domain (NOD)-like receptors (NLRs), and stimulator of IFN genes (STING) [92, 93]. IFN functions in both autocrine and paracrine manners to trigger many immunostimulatory effects following the transcriptional upregulation of IFN-stimulated genes (ISGs). By activating ISG, three major reactions can be initiated, including translation inhibition, mRNA degradation, and transcription and assembly inhibition, to block the viral replication cycle in the host [92-94] (Fig. 4A). Due to their ability to modulate antiviral immune responses, IFNs have been considered as a treatment option for several virus infections, such as hepatitis virus (HBV and HCV), human papillomaviruses (HPVs), and respiratory virus infections (coronavirus and influenza) [95, 96]. Despite IFNs being among the most widely studied and clinically used biopharmaceuticals, their short half-lives and low stability, as well as side effects associated with the drugs' immune-stimulatory function, remain primary limitations on the drugs' adoption and efficacy. Nanoparticle delivery systems aimed at triggering cellular antiviral state for viral inhibition have thus been developed to address the shortcomings of IFNs.

IFN-based drug delivery systems can be divided into nanocarriers that deliver IFN biologics and nanocarriers delivering IFN inducers. The first strategy involves direct encapsulation of IFNs in nanocarriers such as polymeric nanoparticles and liposomes. For instance, Sanchez et al. prepared PLGA-based particles to deliver IFN- $\alpha$ and showed that active IFN- $\alpha$ could be released from the particles in a sustained fashion [97]. As IFN encapsulation shields the biologics from interacting with their cognate plasma membrane-bound receptors, controlled drug release serves to modulate the magnitude and duration 
Fig. 4 A The interferon induction pathways and its downstream functions in inhibiting viral replication. Nanoformulation that inhibit viral replications through the induction of cellular antiviral state include B IFN- $\gamma$ liposomes (adapted from [100]), C IFN- $\alpha$ polymeric nanoparticles (adapted from [97]), D STING agonist nanoparticles (adapted from [108]), and $\mathbf{E}$ CpG-loaded polymeric nanoshell. Adapted from [109], copyright 2020 with permission from Dove Medical Press

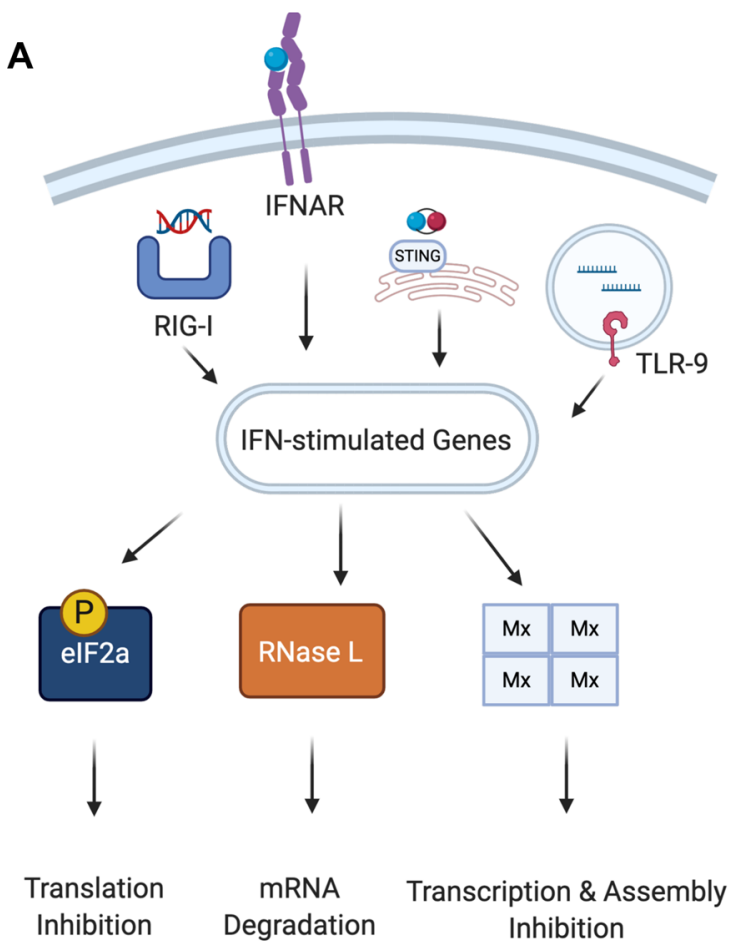

Antiviral State Induction
Antiviral State Induction
B

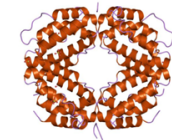

INF-gamma

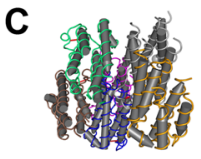

INF-alpha

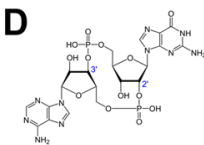

cGMP-AMP

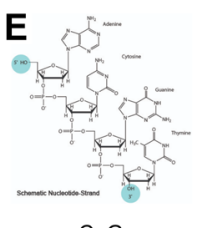

$\mathrm{CpG}$

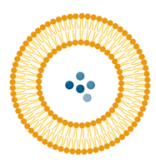

Liposome

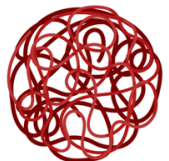

PEG-PLGA Nanoparticles

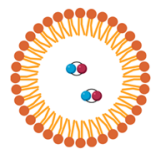

Micelle

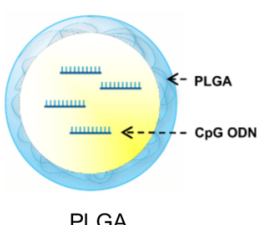

PLGA of IFN responses and can be tuned by the polymeric particles' size, porosity, and degradation profile. Liposomes have also been adopted as a controlled release drug carrier system for IFNs, and liposomal encapsulation has been shown to improve the serum stability of IFN- $\alpha$ and IFN- $\gamma[98,99]$. Saravolac et al. showed that compared with free IFN- $\gamma$ treatment, the liposomal formulation has higher immunomodulatory and antiviral effects as well as reduced toxicity [100]. In a mouse model of murine influenza infection, intranasally administered liposomal IFN- $\gamma$ and free IFN- $\gamma$ resulted in survival rates at $70 \%$ and $20 \%$, respectively, demonstrating superior antiviral effect conferred by the liposomal formulation. The study highlights the potential of exploiting nanocarriers to improve IFN-mediated antiviral protectivity against respiratory infections and is highly relevant in the context of the COVID-19 pandemic.

Aside from delivering IFNs, nanocarrier-mediated delivery of endogenous IFN inducers, such as cyclic dinucleotide cGMP-AMP (cGAMP) and oligodeoxynucleotides with $\mathrm{CpG}$ islands (CpG-ODNs), is another effective strategy in triggering cellular antiviral state. These inducers trigger the innate immune response in cells to upregulate the expression of endogenous IFNs. Among various types of immunomodulators, the agonist of the stimulator of interferon genes (STING agonist) has recently received much scientific and translational interest given their prominent ability to induce typeI IFN [101]. A large variety of lipid-based, polymer-based, and inorganic nanoparticle platforms have been designed to address the delivery challenge of cyclic dinucleotide STING agonists, enabling intracellular delivery of the highly polar molecule to reach the STING ligand located on the endoplasmic reticulum [102]. While the majority of STING-activating nanoparticles have been applied towards vaccination and anticancer immunotherapy [103-107], Aroh et al. showed that cGAMP-loaded nanoparticles could elicit potent and longacting inhibition of multiple HIV-1 isolates in human PBMCs [108]. The antiviral effect of the STING-activating nanoparticle is directly linked to type-I IFN signaling, and the nanoparticle effectively suppressed HIV-1 replication in the PBMCs of HIV-positive patients. In another study that examines the antiviral effect of nanoformulated $\mathrm{CpG}-\mathrm{ODN}$ in chickens, Lin et al. observed that nanoformulated CpG-ODN is more effective than free $\mathrm{CpG}$ at inducing IFN- $\gamma$ as well as other cytokines from bone marrow-derived dendritic cells [109]. The cytokines induced by the $\mathrm{CpG}$ nanoparticle were shown in vitro to significantly suppress the viral protein expression and genome replication of $\mathrm{H} 6 \mathrm{~N} 1$, which is a highly contagious avian influenza virus with prior cases of human transmission [110]. The prominent antiviral efficacies observed in these studies highlight the applicability of immune-stimulating nanoparticles for pandemic control, and coordination of timing, location, magnitude, and duration of innate immune responses via drug delivery systems promises improved clinical benefits over traditional IFN therapy. 


\section{Biomimetic nanoparticles for active targeting of viruses and virus-infected cells}

Besides the previous examples on nanoformulations that deliver host-targeted and pathogen-targeted antiviral, recent advances in biomimetic nanotechnology have further opened up new opportunities for pathogen interception. Blocking host-virus interactions is a common therapeutic strategy that underlies the development of antibody-based therapeutics. However, as viruses possess various mutational strategies, viral mutations may arise and reduce the affinity of antibody drugs. In the case of COVID-19, for instance, emerging variants have begun to exhibit the capability to escape from neutralizing antibodies $[111,112]$. As receptor-mediated binding with surface molecules on the plasma membrane of cells is an indispensable process for viruses to invade host cells [113], this interaction has been exploited to design biomimetic nanoparticle possessing cell-like surfaces for virus targeting. Notably, recent trends in biomimicry and nanoengineering have paved ways to a panoply of nanovesicles and synthetic nanoparticle platforms with cell-like surface chemistries. Unlike antibodies that are designed to target specific viral epitopes, these biomimetic nanoparticles carry viruses' cognate receptors from cells and thus can be agnostic to different viral variants. These cell-like nanocarriers have been widely adopted for drug delivery applications and are gaining interest in anti-infection research [114-122]. The following section highlights advances in biomimetic nanoparticle engineering that exploits the host cell membrane binding in viral pathogenesis for virus targeting (Fig. 5A).

\section{Influenza targeting by biomimetic nanoparticles}

Influenza viruses are negative-sense, single-stranded RNA viruses with well-studied interaction mechanisms against host cell membranes. Depending on different types and subtypes of influenza viruses, the influenza virions display hemagglutinin protein variants, which are glycoproteins with critical functions in viral entry. Hemagglutinin proteins can recognize and bind to exposed sialic acid residues on host cells [123]. The characteristic binding between hemagglutinin and sialic acids underlie the commonly used hemagglutination assay for virus titer detection, in which the presence of influenza viruses causes visible aggregates of red blood cells (RBCs) [124, 125]. Such interaction has inspired the development of sialic acid-conjugated nanoparticles for virus targeting (Fig. 5B). In a reductionist approach, direct conjugation of sialic acids onto nanoparticle surfaces has been shown to bestow inhibitory functions against influenza viruses [127]. Notably, Kwon et al. showed that the spacing between the sialic acid residues on nanoparticle surfaces could influence the particles' binding affinity with influenza viruses, with a spacing of around $3 \mathrm{~nm}$ exhibiting the strongest binding to hemagglutinin trimers. Intranasal administration of the sialic acid-functionalized particles in mice infected with $\mathrm{H} 1 \mathrm{~N} 1$ resulted in reduced viral load in the lungs as well as improved survival. An alternative approach to enable nanoparticle targeting of influenza was demonstrated by Chen et al., who applied erythrocyte membrane cloaked nanoparticles for nanoparticle functionalization [128]. In the study, the dense glycan content on the exoplasmic side of the red blood cell membrane
Fig. 5 A Schematic presentation of biomimetic nanoparticle designs for targeting both virus and virally infected host cells. Examples of cell membranecloaked nanoparticles for specific virus targeting include $\mathbf{B}$ red blood cell membrane-coated particles for influenza targeting [127], C CD4 T cell membranecoated particles for HIV targeting [133], and $\mathbf{D}$ mosquito cell membrane-wrapped particles for Zika virus targeting [138]. TEM pictures in the insets are cited with permission from [121, 127]. Copyright 2017 American Chemical Society

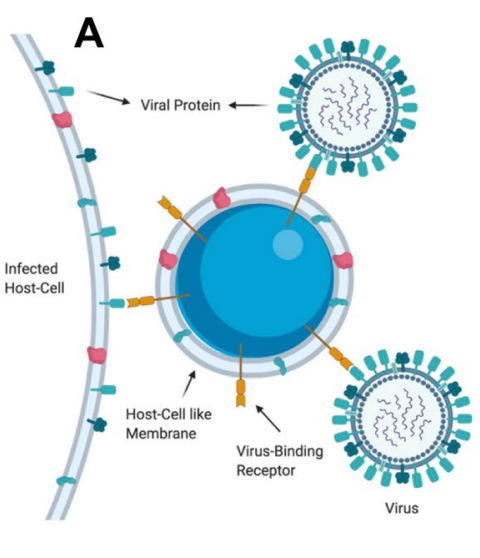

Targeting strategies Viral and infected host cell

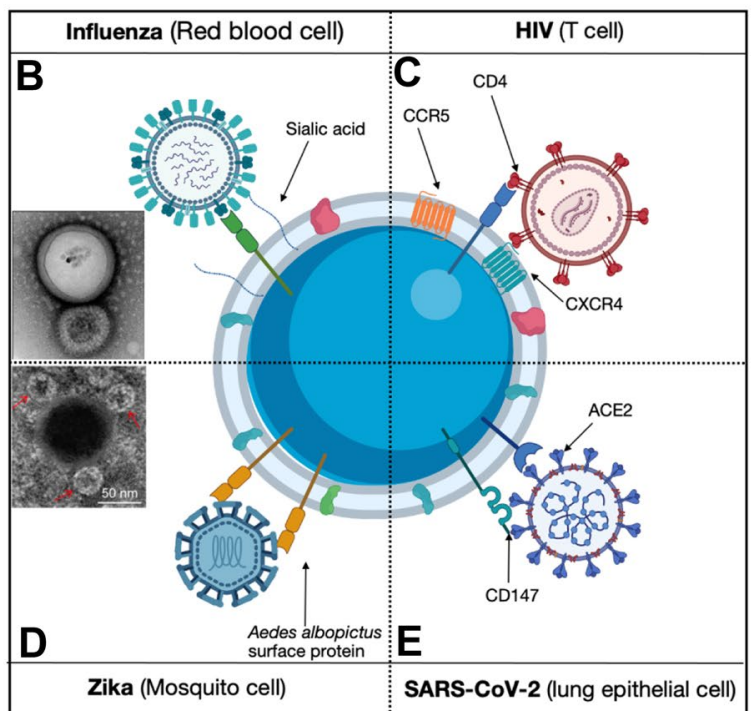


was found to facilitate right-side-out membrane orientation on PLGA nanoparticles, thereby exposing terminal sialic acids on the glycans for influenza virus targeting. Incorporation of magnetic functionalities via encapsulation of superparamagnetic iron oxide nanoparticles in the PLGA cores allowed for virus isolation and enrichment, enabling enhanced pathogen detection via several different diagnostic assays. Towards enhancing red blood cell membrane-cloaked nanoparticles for influenza virus targeting, Nie et al. demonstrated that particles with spikes between 5 and $10 \mathrm{~nm}$ could bind more effectively with influenza viruses as compared with particles with smooth surfaces upon cell membrane cloaking [129]. The enhanced binding is attributed to an interlocking mechanism between the spiky nanostructure and virus glycoproteins. More recently, structural insight towards improving virus targeting efficiency has led to the development of cell membrane-cloaked nanobowls that matches the topology of viruses for enhanced viral inhibitions [41, 126]. These examples highlight the versatility of nanocarriers for advancing antiviral treatments.

\section{HIV targeting by biomimetic nanoparticles}

HIV infects human leukocytes through direct binding between its gp120 protein and the CD4, CCR5, and CXCR4 receptors on CD4+ T cells [130]. The interaction has inspired the development of biomimetic nanodecoy and drug delivery strategies to suppress HIV-1 infection (Fig. 5C). Bronshtein et al. demonstrated in a proof-ofprinciple study of exploiting cell-derived liposomes displaying surface CCR5 to target gp120-expressing cells [131]. With CCR5 being the cognate ligand of gp120, CCR5-laden membrane vesicles were shown to target gp120-expressing cells more effectively, which serve as a mimic of HIV-infected cells. Delivery of EDTA by the CCR5-displaying liposomes showed a drastic difference in cytotoxicity between the gp120-expressing cells and control cells, thereby supporting the concept of biomimetic drug delivery towards infected host cells. De Carvalho et al. further demonstrated that CD4+ T cells secreted exosomes can act as a nanodecoy to block HIV entry into host cells. These exosomes have the same surface proteosome as their source CD4+ T cells, and they can effectively attach to HIV-1 and preclude viral binding with healthy $\mathrm{CD} 4+\mathrm{T}$ cells. In addition, exosomes released from specific host cells have also been utilized to suppress bacterial and parasitic invasion of specific host cells [132]. Wei et al. constructed T cellmembrane-coated nanoparticles (TNPs) by wrapping polymeric cores with natural CD4+ T cell membranes, which contain critical antigens such as CCR5 and CXCR4 receptors for HIV viral targeting. The TNPs act as decoys for viral attack and neutralize HIV by diverting the viruses away from their intended host targets [133]. Moreover, Zhang et al. investigated the potential of nanoengineered CD4+ TNPs to neutralize a broad range of HIV-1 strains, showing that the nanodecoys can neutralize all of the 125 HIV-1-pseudotyped viruses tested in the study. Furthermore, the nanodecoys can selectively bind to infected cells and decrease the release of HIV-1 particles through an autophagy-dependent mechanism with no drug-induced off-target or cytotoxic effects on bystander cells [134].

\section{Zika virus targeting by biomimetic nanoparticles}

Zika virus (ZIKV) is another major infectious pathogen that caused a widespread epidemic in 2015 [135, 136], and with no approved vaccine or treatment available against ZIKV, biomimetic nanocarrier has been adopted for anti-ZIKV neutralization. Rao et al. showed that mosquito host-cell membrane-wrapped nanoparticles effectively trap ZIKV and divert it away from its cellular targets (Fig. 5D). Of note, compared with cell membrane-derived vesicles, the cell membrane-coated nanoparticles display reduced susceptibility to membrane fusion, thereby obviating inadvertent transfer of detained pathogens to host cells. With increasing understanding of the virus-host interactions behind ZIKV, membrane receptors (i.e., AXL, TIM-1, DC-SIGN) and human cell types (i.e., endothelial cells, dermal fibroblasts, and dendritic cells) have been identified as primary protein and cellular targets for the virus [137]. It may thus be envisioned that a nanodecoy constructed with engineered human cells may offer similar treatment advantages toward clinical adoption.

\section{SARS-CoV-2 targeting by biomimietic nanoparticles}

The evolution and continued development of the biomimetic nanodecoy technology led to rapid nanotechnologybased responses following the outbreak of the COVID-19 pandemic. Within months following the identification of the host-pathogen interaction mechanism behind SARSCoV-2, Zhang et al. showed that the cellular nanosponges derived from human lung epithelial type II cells or human macrophages could neutralize SARS-CoV-2 and make the coronaviruses unable to infect their usual cellular targets [138]. Nanosponges derived from both lung epithelial cells and macrophages display ACE2, and upon incubation with SARS-CoV-2 the nanosponges readily neutralize the viruses. Based on a similar approach, Rao et al. demonstrated that ACE2-displaying membrane vesicles could be derived from genetically engineered $293 \mathrm{~T}$ cells, which provide a more readily available source for the membrane vesicle [139]. Such genetic engineering approach has also been adopted to generate $\mathrm{hNTCP}$-overexpressing nanovesicles for HBV treatment [140]. In the study against SARS-CoV2, in addition to using 
ACE2 membrane vesicles, Rao et al. further incorporated membrane vesicles derived from macrophage cells, which were previously shown to bind and neutralize cytokine factors associated with inflammatory responses [141]. The resulting hybrid nanovesicles exhibit the combined function of virus neutralization and suppression of inflammation-associated lung injury. These approaches highlight how nanotechnology solutions can be rapidly adapted to respond to emerging viral threats. Notable among these membrane-derived nanodecoy strategies is that the nanoparticles can, in principle, be agnostic to receptor binding phenotypes and resistant to viral mutations as these nanoparticles contain all the membrane surface proteins of host cells (Fig. 5E). Incorporation of drug payloads into these biomimetic nanoparticles can be envisioned to enhance antiviral delivery to SARS-CoV-2 viruses and virus-infected host cells.

\section{Conclusion and future perspective}

The COVID-19 pandemic serves as a sobering reminder of the ongoing battle against viral pathogens, their threat to public health, and the potential socioeconomic burden that necessitates continuing innovation and research efforts for new therapeutic interventions. Major breakthroughs in drug delivery nanotechnology have been introduced since the 2000s, and the plethora and drug delivery strategies enabled by nanocarriers have transformed the way we envision treatment strategies and clinical regimens. Nanomedicine has come a long way in terms of fabrication techniques, material design, payload incorporation, and surface functionalization. Furthermore, nanoparticles promise to vastly improve antiviral drugs' pharmacokinetics, synergism, and targeting specificity. The present review highlights multiple distinctive antiviral treatment modalities made possible by nanocarriers, including long-acting drug delivery, combinational drug delivery, and targeted drug delivery, and the prospect of enabling broad-spectrum antiviral intervention is discussed. Upon examining the current clinical landscape for SARS-CoV-2 treatments, in which many small-molecule antivirals have shown unsatisfactory treatment outcomes [5], the need to advance nanoformulated antivirals along with all their promised benefits to the clinics is compelling. For instance, combinational antiviral treatments are under investigation in many anti-COVID19 clinical trials [57, 142], and it can be envisioned that nanocarriers can be engineered to incorporate these antiviral compounds to promote therapeutic synergism [143, 144]. Such effort warrants cohesive collaboration among engineers, virologists, and clinicians, as well as increased awareness of infectious diseases by the general public, funding agencies, and investors going forward. Currently, there are two nanoparticle-based antivirals in clinical trials, including lactoferrin liposomes (Clinical
Trial \#NCT04475120) and remdesivir nanoparticles (Clinical Trial \#NCT04480333), which function by inhibiting viral replication and reducing inflammation, respectively. Compared with the hundreds of ongoing anti-COVID19 clinical trials based on small molecule and antibody drugs, the potential of antiviral nanotechnology remains relatively untapped. We anticipate that the present pandemic to bring forth increasing effort towards adopting nanotechnology for infectious disease preparedness.

Although the present review covers a large body of literature on nanoparticle-based drug delivery directed toward antiviral applications, developmental efforts on antiviral nanoparticles represent a small portion of nanomedicine research compared with those against oncological disease [145]. One reason behind such bias lies in the added difficulty in handling experiments involving virus infections. Unlike cancer models that can be operated in Biosafety Level 1 (BSL-1) facilities, virus infection experiments are handled at BSL-2 and BLS-3 facilities depending on the infectiousness of the pathogens. Such requirement adds regulatory and technical hurdles to chemists and engineers, and additional training and cooperation with laboratories specialized in virology research are warranted to facilitate antiviral nanomedicine development. Inconsistent funding and investment interest are other hurdles that thwart antiviral nanotechnology. Unlike the persistently high-profile medical challenge of cancer that has brought forth major funding campaigns such as War on Cancer [146], the NCI Alliance for Nanotechnology in Cancer [147], and Cancer Moonshot in the United States [147], the sporadic and unpredictable nature of viral pandemics may divert funding support and research enthusiasm away in non-pandemic times. As we witness how funding efforts by philanthropic foundations and global vaccine alliances have accelerated vaccine rollout during the COVID-19 pandemic, a similar funding campaign would assure rapid incorporation of nanotechnology in future antiviral treatments. With more than 20 nanoparticle-based pharmaceutics being used for clinical treatment of oncological disease [148], we expect continuing antiviral nanomedicine research to likewise benefit pandemic preparedness. As the COVID-19 shows the severe havoc that can be wreaked by a global virus outbreak, treatment benefits conferred by nanocarrier technology may translate to millions of lives saved in hospitals.

Acknowledgements We acknowledge Dr. Hui-Wen Chen at the National Taiwan University for insightful discussions on antiviral research.

Author contribution Kai-Chieh Yang: writing-original draft, writing—review \& editing. Jung-Chen Lin: writing—original draft. Hsiao-Han Tsai: writing - original draft. Chung-Yao Hsu: writingoriginal draft. Vicky Shih: writing—original draft. Che-Ming Jack Hu: writing — original draft, writing—review \& editing. 
Funding The work is supported by the Ministry of Science and Technology, Taiwan (108-2119-M-001-016 and 109-2321-B-002-033) and Academia Sinica Career Development Award (AS-CDA-105-L06).

\section{Declarations}

Consent for publication Consent for publication has been acquired from original publishers for the cited figures in the manuscript.

Competing interests The authors declare that they have no competing interest.

\section{References}

1. Taxonomic. International Committee on Taxonomy of Viruses (ICTV). 2020. https://talk.ictvonline.org/taxonomy/

2. Breitbart M, Rohwer F. Here a virus, there a virus, everywhere the same virus? Trends Microbiol. 2005;13(6):278-84. https:// doi.org/10.1016/j.tim.2005.04.003.

3. Bryan-Marrugo OL, Ramos-Jiménez J, Barrera-Saldaña H, Rojas-Martínez A, Vidaltamayo R, Rivas-Estilla AM. History and progress of antiviral drugs: from acyclovir to direct-acting antiviral agents (DAAs) for Hepatitis C. Medicina Universitaria. 2015;17(68):165-74. https://doi.org/10.1016/j.rmu.2015.05.003.

4. Rodriguez Mega E. COVID has killed more than one million people. How many more will die? Nature. 2020. https://doi.org/ 10.1038/d41586-020-02762-y.

5. Organization WH. "Solidarity" clinical trial for COVID-19 treatments. 2020.

6. Hubsher G, Haider M, Okun MS. Amantadine: the journey from fighting flu to treating Parkinson disease. Neurology. 2012;78(14):10969. https://doi.org/10.1212/WNL.0b013e31824e8f0d.

7. Ruiz-Hitzky E, Darder M, Wicklein B, Ruiz-Garcia C, MartinSampedro R, Del Real G, et al. Nanotechnology responses to COVID-19. Adv Healthc Mater. 2020;9(19):e2000979. https:// doi.org/10.1002/adhm.202000979.

8. Talebian S, Wallace GG, Schroeder A, Stellacci F, Conde J. Nanotechnology-based disinfectants and sensors for SARSCoV-2. Nat Nanotechnol. 2020;15(8):618-21. https://doi.org/ 10.1038/s41565-020-0751-0.

9. Chung YH, Beiss V, Fiering SN, Steinmetz NF. COVID-19 vaccine frontrunners and their nanotechnology design. ACS Nano. 2020;14(10):12522-37. https://doi.org/10.1021/acsnano.0c07197.

10. Tang Z, Kong N, Zhang X, Liu Y, Hu P, Mou S et al. A materials-science perspective on tackling COVID-19. Nat Rev Mater. 2020:1-14. https://doi.org/10.1038/s41578-020-00247-y

11. Zhou J, Krishnan N, Jiang Y, Fang RH, Zhang L. Nanotechnology for virus treatment. Nano Today. 2021;36:101031. https:// doi.org/10.1016/j.nantod.2020.101031.

12. Let's talk about lipid nanoparticles. Nat Rev Mater. 2021;6(2):99-. https://doi.org/10.1038/s41578-021-00281-4

13. Más V. Melero JA. Entry of Enveloped Viruses into Host Cells: Membrane fusion. Structure and Physics of viruses. Subcellular Biochemistry; 2013. p. 467-87.

14. Yang J, Petitjean SJL, Koehler M, Zhang Q, Dumitru AC, Chen $\mathrm{W}$, et al. Molecular interaction and inhibition of SARS-CoV-2 binding to the ACE2 receptor. Nat Commun. 2020;11(1):4541. https://doi.org/10.1038/s41467-020-18319-6.

15. Blaas D. Viral entry pathways: the example of common cold viruses. Wien Med Wochenschr. 2016;166(7-8):211-26. https:// doi.org/10.1007/s10354-016-0461-2.
16. Gao Y, Yan L, Huang Y, Liu F, Zhao Y, Cao L, et al. Structure of the RNA-dependent RNA polymerase from COVID-19 virus. Science. 2020;368(6492):779-82. https://doi.org/10.1126/ science.abb7498.

17. Yin W, Mao C, Luan X, Shen DD, Shen Q, Su H, et al. Structural basis for inhibition of the RNA-dependent RNA polymerase from SARS-CoV-2 by remdesivir. Science. 2020;368(6498):1499504. https://doi.org/10.1126/science.abc1560.

18. Barman S, Ali A, Hui EK, Adhikary L, Nayak DP. Transport of viral proteins to the apical membranes and interaction of matrix protein with glycoproteins in the assembly of influenza viruses. Virus Res. 2001;77(1):61-9. https://doi.org/10.1016/s01681702(01)00266-0.

19. Jacob JR, Mansfield K, You JE, Tennant BC, Kim YH. Natural iminosugar derivatives of 1-deoxynojirimycin inhibit glycosylation of hepatitis viral envelope proteins. J Microbiol. 2007;45(5):431-40.

20. Eastman RT, Roth JS, Brimacombe KR, Simeonov A, Shen M, Patnaik S, et al. Remdesivir: a review of its discovery and development leading to emergency use authorization for treatment of COVID-19. ACS Cent Sci. 2020;6(5):672-83. https://doi.org/10. 1021/acscentsci.0c00489.

21. Milovanovic M, Arsenijevic A, Milovanovic J, Kanjevac T, Arsenijevic N. Nanoparticles in antiviral therapy. In: Grumezescu AM, editor. Antimicrobial Nanoarchitectonics. Elsevier; 2017. p. 383-410.

22. Lembo D, Cavalli R. Nanoparticulate delivery systems for antiviral drugs. Antivir Chem Chemother. 2010;21(2):53-70. https:// doi.org/10.3851/IMP1684.

23. Singh L, Kruger HG, Maguire GEM, Govender T, Parboosing R. The role of nanotechnology in the treatment of viral infections. Ther Adv Infect Dis. 2017;4(4):105-31. https://doi.org/10.1177/ 2049936117713593.

24. Nasrollahzadeh M, Sajjadi M, Soufi GJ, Iravani S, Varma RS. Nanomaterials and nanotechnology-associated innovations against viral infections with a focus on coronaviruses. Nanomaterials (Basel). 2020;10(6). https://doi.org/10.3390/nano10061072.

25. Gurunathan S, Qasim M, Choi Y, Do JT, Park C, Hong K et al. Antiviral potential of nanoparticles-can nanoparticles fight against coronaviruses? Nanomaterials (Basel). 2020;10(9). https://doi.org/10.3390/nano10091645.

26. Belletti D, Tosi G, Forni F, Gamberini MC, Baraldi C, Vandelli MA, et al. Chemico-physical investigation of tenofovir loaded polymeric nanoparticles. Int J Pharm. 2012;436(1-2):753-63. https://doi.org/10.1016/j.ijpharm.2012.07.070.

27. Puligujja P, Balkundi SS, Kendrick LM, Baldridge HM, Hilaire JR, Bade AN, et al. Pharmacodynamics of long-acting folic acid-receptor targeted ritonavir-boosted atazanavir nanoformulations. Biomaterials. 2015;41:141-50. https://doi.org/10.1016/j. biomaterials.2014.11.012.

28. Mandal S, Belshan M, Holec A, Zhou Y, Destache CJ. An Enhanced emtricitabine-loaded long-acting nanoformulation for prevention or treatment of HIV infection. Antimicrob Agents Chemother. 2017;61(1). https://doi.org/10.1128/AAC.01475-16.

29. Mandal S, Prathipati PK, Belshan M, Destache CJ. A potential long-acting bictegravir loaded nano-drug delivery system for HIV-1 infection: a proof-of-concept study. Antiviral Res. 2019;167:83-8. https://doi.org/10.1016/j.antiviral.2019.04.007.

30. Gagne JF, Desormeaux A, Perron S, Tremblay MJ, Bergeron MG. Targeted delivery of indinavir to HIV-1 primary reservoirs with immunoliposomes. Biochim Biophys Acta. 2002;1558(2):198-210. https://doi.org/10.1016/s0005-2736(01) 00432-1.

31. ÖZtÜRk AA, KirimlioĞLu GY. Preparation and in vitro characterization of lamivudine loaded nanoparticles prepared by acid 
and/or ester terminated PLGA for effective oral anti-retroviral therapy. Journal of Research in Pharmacy. 2019;23(5):897-913. https://doi.org/10.35333/jrp.2019.37.

32. das Neves J, Michiels J, Ariën KK, Vanham G, Amiji M, Bahia $\mathrm{MF}$, et al. Polymeric Nanoparticles Affect the Intracellular Delivery, Antiretroviral Activity and Cytotoxicity of the Microbicide Drug Candidate Dapivirine. Pharm Res. 2011;29(6):1468-84. https://doi.org/10.1007/s11095-011-0622-3.

33. Gong Y, Zhi K, Nagesh PKB, Sinha N, Chowdhury P, Chen H et al. An elvitegravir nanoformulation crosses the blood-brain barrier and suppresses HIV-1 replication in microglia. Viruses. 2020;12(5). https://doi.org/10.3390/v12050564

34. Clayton R, Ohagen A, Nicol F, Del Vecchio AM, Jonckers TH, Goethals $\mathrm{O}$, et al. Sustained and specific in vitro inhibition of HIV-1 replication by a protease inhibitor encapsulated in gp120targeted liposomes. Antiviral Res. 2009;84(2):142-9. https://doi. org/10.1016/j.antiviral.2009.08.003.

35. Tang X, Liang Y, Liu X, Zhou S, Liu L, Zhang F, et al. PLGAPEG nanoparticles coated with anti-CD45RO and loaded with HDAC plus protease inhibitors activate latent HIV and inhibit viral spread. Nanoscale Res Lett. 2015;10(1):413. https://doi.org/ 10.1186/s11671-015-1112-z.

36. Asasutjarit R, Managit C, Phanaksri T, Treesuppharat W, Fuongfuchat A. Formulation development and in vitro evaluation of transferrin-conjugated liposomes as a carrier of ganciclovir targeting the retina. Int J Pharm. 2020;577:119084. https://doi. org/10.1016/j.ijpharm.2020.119084.

37. Mandal S, Kang G, Prathipati PK, Fan W, Li Q, Destache CJ. Long-acting parenteral combination antiretroviral loaded nanodrug delivery system to treat chronic HIV-1 infection: a humanized mouse model study. Antiviral Res. 2018;156:85-91. https:// doi.org/10.1016/j.antiviral.2018.06.005.

38. Kumar P, Lakshmi YS, Kondapi AK. Triple drug combination of zidovudine, efavirenz and lamivudine loaded lactoferrin nanoparticles: an effective nano first-line regimen for HIV therapy. Pharm Res. 2017;34(2):257-68. https://doi.org/10.1007/ s11095-016-2048-4.

39. Duan J, Freeling JP, Koehn J, Shu C, Ho RJ. Evaluation of atazanavir and darunavir interactions with lipids for developing $\mathrm{pH}-$ responsive anti-HIV drug combination nanoparticles. J Pharm Sci. 2014;103(8):2520-9. https://doi.org/10.1002/jps.24046.

40. Freeling JP, Koehn J, Shu C, Sun J, Ho RJ. Anti-HIV drugcombination nanoparticles enhance plasma drug exposure duration as well as triple-drug combination levels in cells within lymph nodes and blood in primates. AIDS Res Hum Retroviruses. 2015;31(1):107-14. https://doi.org/10.1089/aid.2014.0210.

41. Hu CJ, Chen YT, Fang ZS, Chang WS, Chen HW. Antiviral efficacy of nanoparticulate vacuolar ATPase inhibitors against influenza virus infection. Int J Nanomedicine. 2018;13:8579-93. https://doi.org/10.2147/IJN.S185806.

42. Kim SS, Peer D, Kumar P, Subramanya S, Wu H, Asthana D, et al. RNAi-mediated CCR5 silencing by LFA-1-targeted nanoparticles prevents HIV infection in BLT mice. Mol Ther. 2010;18(2):370-6. https://doi.org/10.1038/mt.2009.271.

43. Thi EP, Mire CE, Lee AC, Geisbert JB, Zhou JZ, Agans KN, et al. Lipid nanoparticle siRNA treatment of Ebola-virus-Makonainfected nonhuman primates. Nature. 2015;521(7552):362-5. https://doi.org/10.1038/nature14442.

44. Wang J, Feng SS, Wang S, Chen ZY. Evaluation of cationic nanoparticles of biodegradable copolymers as siRNA delivery system for hepatitis B treatment. Int J Pharm. 2010;400(1-2):194-200. https://doi.org/10.1016/j.ijpharm.2010.08.026.

45. Kim SI, Shin D, Lee H, Ahn BY, Yoon Y, Kim M. Targeted delivery of siRNA against hepatitis $\mathrm{C}$ virus by apolipoprotein A-I-bound cationic liposomes. J Hepatol. 2009;50(3):479-88. https://doi.org/10.1016/j.jhep.2008.10.029.
46. Steinbach JM, Weller CE, Booth CJ, Saltzman WM. Polymer nanoparticles encapsulating siRNA for treatment of HSV-2 genital infection. J Control Release. 2012;162(1):102-10. https://doi. org/10.1016/j.jconrel.2012.06.008.

47. Kulkarni TA, Bade AN, Sillman B, Shetty BLD, Wojtkiewicz MS, Gautam N, et al. A year-long extended release nanoformulated cabotegravir prodrug. Nat Mater. 2020;19(8):910-20. https://doi.org/10.1038/s41563-020-0674-z.

48. das Neves J, Michiels J, Arien KK, Vanham G, Amiji M, Bahia $\mathrm{MF}$, et al. Polymeric nanoparticles affect the intracellular delivery, antiretroviral activity and cytotoxicity of the microbicide drug candidate dapivirine. Pharm Res. 2012;29(6):1468-84. https://doi.org/10.1007/s11095-011-0622-3.

49. Nowacek AS, Miller RL, McMillan J, Kanmogne G, Kanmogne M, Mosley RL, et al. NanoART synthesis, characterization, uptake, release and toxicology for human monocyte-macrophage drug delivery. Nanomedicine (Lond). 2009;4(8):903-17. https://doi.org/10.2217/nnm.09.71.

50. Dash PK, Gendelman HE, Roy U, Balkundi S, Alnouti Y, Mosley RL, et al. Long-acting nanoformulated antiretroviral therapy elicits potent antiretroviral and neuroprotective responses in HIV-1-infected humanized mice. AIDS. 2012;26(17):2135-44. https://doi.org/10.1097/QAD. 0b013e328357f5ad.

51. Hobson JJ, Al-Khouja A, Curley P, Meyers D, Flexner C, Siccardi M, et al. Semi-solid prodrug nanoparticles for longacting delivery of water-soluble antiretroviral drugs within combination HIV therapies. Nat Commun. 2019;10(1):1413. https://doi.org/10.1038/s41467-019-09354-z.

52. Gousseff M, Penot P, Gallay L, Batisse D, Benech N, Bouiller $\mathrm{K}$, et al. Clinical recurrences of COVID-19 symptoms after recovery: viral relapse, reinfection or inflammatory rebound? J Infect. 2020;81(5):816-46. https://doi.org/10.1016/j.jinf.2020. 06.073.

53. Feng M, Cai Q, Huang H, Zhou P. Liver targeting and anti-HBV activity of reconstituted HDL-acyclovir palmitate complex. Eur J Pharm Biopharm. 2008;68(3):688-93. https://doi.org/10.1016/j.ejpb.2007. 07.005 .

54. Azarmi S, Roa WH, Lobenberg R. Targeted delivery of nanoparticles for the treatment of lung diseases. Adv Drug Deliv Rev. 2008;60(8):863-75. https://doi.org/10.1016/j.addr.2007.11.006.

55. Zhao Z, Ukidve A, Krishnan V, Fehnel A, Pan DC, Gao Y, et al. Systemic tumour suppression via the preferential accumulation of erythrocyte-anchored chemokine-encapsulating nanoparticles in lung metastases. Nat Biomed Eng. 2020. https://doi.org/10. 1038/s41551-020-00644-2.

56. Wang W, Xu Y, Gao R, Lu R, Han K, Wu G, et al. Detection of SARS-CoV-2 in different types of clinical specimens. JAMA. 2020;323(18):1843-4. https://doi.org/10.1001/jama.2020.3786.

57. Hung IF, Lung KC, Tso EY, Liu R, Chung TW, Chu MY, et al. Triple combination of interferon beta- $1 \mathrm{~b}$, lopinavir-ritonavir, and ribavirin in the treatment of patients admitted to hospital with COVID-19: an open-label, randomised, phase 2 trial. Lancet. 2020;395(10238):1695-704. https://doi.org/10.1016/S01406736(20)31042-4.

58. Perelson AS, Essunger P, Cao Y, Vesanen M, Hurley A, Saksela $\mathrm{K}$, et al. Decay characteristics of HIV-1-infected compartments during combination therapy. Nature. 1997;387(6629):188-91. https://doi.org/10.1038/387188a0.

59. Zhang L, Ramratnam B, Tenner-Racz K, He Y, Vesanen $\mathrm{M}$, Lewin S, et al. Quantifying residual HIV-1 replication in patients receiving combination antiretroviral therapy. $\mathrm{N}$ Engl J Med. 1999;340(21):1605-13. https://doi.org/10.1056/ NEJM199905273402101.

60. Shibata A, McMullen E, Pham A, Belshan M, Sanford B, Zhou Y, et al. Polymeric nanoparticles containing combination 
antiretroviral drugs for HIV type 1 treatment. AIDS Res Hum Retroviruses. 2013;29(5):746-54. https://doi.org/10.1089/AID. 2012.0301.

61. Jackson LA, Anderson EJ, Rouphael NG, Roberts PC, Makhene $\mathrm{M}$, Coler RN, et al. An mRNA vaccine against SARS-CoV-2preliminary report. N Engl J Med. 2020;383(20):1920-31. https://doi.org/10.1056/NEJMoa2022483.

62. Mulligan MJ, Lyke KE, Kitchin N, Absalon J, Gurtman A, Lockhart S, et al. Phase I/II study of COVID-19 RNA vaccine BNT162b1 in adults. Nature. 2020;586(7830):589-93. https://doi.org/10.1038/ s41586-020-2639-4.

63. Levanova A, Poranen MM. RNA interference as a prospective tool for the control of human viral infections. Front Microbiol. 2018;9:2151. https://doi.org/10.3389/fmicb.2018.02151.

64. Kanasty R, Dorkin JR, Vegas A, Anderson D. Delivery materials for siRNA therapeutics. Nat Mater. 2013;12(11):967-77. https:// doi.org/10.1038/nmat3765.

65. Zhang W, Yang H, Kong X, Mohapatra S, Juan-Vergara HS, Hellermann $\mathrm{G}$ et al. Erratum: inhibition of respiratory syncytial virus infection with intranasal siRNA nanoparticles targeting the viral NS1 gene. Nat Med. 2005;11(2):233-. https://doi.org/10. 1038/nm0205-233b

66. Jamali A, Mottaghitalab F, Abdoli A, Dinarvand M, Esmailie A, Kheiri MT, et al. Inhibiting influenza virus replication and inducing protection against lethal influenza virus challenge through chitosan nanoparticles loaded by siRNA. Drug Deliv Transl Res. 2018;8(1):12-20. https://doi.org/10.1007/s13346-017-0426-z.

67. Ji X, Li Z. Medicinal chemistry strategies toward host targeting antiviral agents. Med Res Rev. 2020;40(5):1519-57. https://doi. org/10.1002/med.21664.

68. Staring J, Raaben M, Brummelkamp TR. Viral escape from endosomes and host detection at a glance. J Cell Sci. 2018;131(15). https://doi.org/10.1242/jcs.216259.

69. Samuel CE. Antiviral actions of interferons. Clin Microbiol Rev. 2001;14(4):778-809. https://doi.org/10.1128/CMR.14.4. 778-809.2001 (table of contents).

70. Al-Bari MAA. Targeting endosomal acidification by chloroquine analogs as a promising strategy for the treatment of emerging viral diseases. Pharmacol Res Perspect. 2017;5(1):e00293. https://doi.org/10.1002/prp2.293.

71. Hu TY, Frieman M, Wolfram J. Insights from nanomedicine into chloroquine efficacy against COVID-19. Nat Nanotechnol. 2020;15(4):247-9. https://doi.org/10.1038/s41565-020-0674-9.

72. Yang N, Shen HM. Targeting the endocytic pathway and autophagy process as a novel therapeutic strategy in COVID19. Int J Biol Sci. 2020;16(10):1724-31. https://doi.org/10.7150/ ijbs. 45498 .

73. Wu F, Zhao S, Yu B, Chen YM, Wang W, Song ZG, et al. A new coronavirus associated with human respiratory disease in China. Nature. 2020;579(7798):265-9. https://doi.org/10.1038/ s41586-020-2008-3.

74. Zhao H, To KKW, Sze KH, Yung TT, Bian M, Lam H, et al. A broad-spectrum virus- and host-targeting peptide against respiratory viruses including influenza virus and SARS-CoV-2. Nat Commun. 2020;11(1):4252. https://doi.org/10.1038/ s41467-020-17986-9.

75. Wolfram J, Nizzero S, Liu H, Li F, Zhang G, Li Z, et al. A chloroquine-induced macrophage-preconditioning strategy for improved nanodelivery. Sci Rep. 2017;7(1):13738. https://doi. org/10.1038/s41598-017-14221-2.

76. Maisonnasse P, Guedj J, Contreras V, Behillil S, Solas C, Marlin $\mathrm{R}$, et al. Hydroxychloroquine use against SARS-CoV-2 infection in non-human primates. Nature. 2020;585(7826):584-7. https:// doi.org/10.1038/s41586-020-2558-4.

77. Savarino A, Boelaert JR, Cassone A, Majori G, Cauda R. Effects of chloroquine on viral infections: an old drug against today's diseases? Lancet Infect Dis. 2003;3(11):722-7. https://doi.org/ 10.1016/s1473-3099(03)00806-5.

78. Keyaerts E, Li S, Vijgen L, Rysman E, Verbeeck J, Van Ranst M, et al. Antiviral activity of chloroquine against human coronavirus OC43 infection in newborn mice. Antimicrob Agents Chemother. 2009;53(8):3416-21. https://doi.org/10.1128/AAC.01509-08.

79. Chen Z, Hu J, Zhang Z, Jiang S, Han S, Yan D et al. Efficacy of hydroxychloroquine in patients with COVID-19: results of a randomized clinical trial. medRxiv. 2020:2020.03.22.20040758. https://doi.org/10.1101/2020.03.22.20040758

80. Fan J, Zhang X, Liu J, Yang Y, Zheng N, Liu Q, et al. Connecting hydroxychloroquine in vitro antiviral activity to in vivo concentration for prediction of antiviral effect: a critical step in treating COVID-19 patients. Clin Infect Dis. 2020. https://doi. org/10.1093/cid/ciaa623.

81. Tai TT, Wu TJ, Wu HD, Tsai YC, Wang HT, Wang AM, et al. A Strategy to treat COVID-19 disease with targeted delivery of inhalable liposomal hydroxychloroquine: a preclinical pharmacokinetic study. Clin Transl Sci. 2020. https://doi.org/10.1111/ cts. 12923.

82. Fotoran WL, Muntefering T, Kleiber N, Miranda BNM, Liebau E, Irvine DJ, et al. A multilamellar nanoliposome stabilized by interlayer hydrogen bonds increases antimalarial drug efficacy. Nanomedicine. 2019;22:102099. https://doi.org/10.1016/j.nano. 2019.102099.

83. Bimbo LM, Denisova OV, Makila E, Kaasalainen M, De Brabander JK, Hirvonen J, et al. Inhibition of influenza A virus infection in vitro by saliphenylhalamide-loaded porous silicon nanoparticles. ACS Nano. 2013;7(8):6884-93. https://doi.org/ 10.1021/nn402062f.

84. Hu CJ, Chang WS, Fang ZS, Chen YT, Wang WL, Tsai HH, et al. Nanoparticulate vacuolar ATPase blocker exhibits potent hosttargeted antiviral activity against feline coronavirus. Sci Rep. 2017;7(1):13043. https://doi.org/10.1038/s41598-017-13316-0.

85. Chen HW, Cheng JX, Liu MT, King K, Peng JY, Zhang XQ, et al. Inhibitory and combinatorial effect of diphyllin, a v-ATPase blocker, on influenza viruses. Antiviral Res. 2013;99(3):371-82. https://doi.org/10.1016/j.antiviral.2013.06.014.

86. Martinez-Lopez A, Persaud M, Chavez MP, Zhang H, Rong L, Liu S, et al. Glycosylated diphyllin as a broad-spectrum antiviral agent against Zika virus. EBioMedicine. 2019;47:269-83. https://doi.org/10.1016/j.ebiom.2019.08.060.

87. Paltrinieri S, Giordano A, Stranieri A, Lauzi S. Feline infectious peritonitis (FIP) and coronavirus disease 19 (COVID-19): are they similar? Transbound Emerg Dis. 2020. https://doi.org/10. 1111/tbed.13856.

88. Monk PD, Marsden RJ, Tear VJ, Brookes J, Batten TN, Mankowski M, et al. Safety and efficacy of inhaled nebulised interferon beta-1a (SNG001) for treatment of SARS-CoV-2 infection: a randomised, double-blind, placebo-controlled, phase 2 trial. Lancet Respir Med. 2020. https://doi.org/10.1016/S22132600(20)30511-7.

89. Zhang Q, Bastard P, Liu Z, Le Pen J, Moncada-Velez M, Chen J et al. Inborn errors of type I IFN immunity in patients with lifethreatening COVID-19. Science. 2020;370(6515). doi:https://doi. org/10.1126/science.abd4570.

90. Bastard P, Rosen LB, Zhang Q, Michailidis E, Hoffmann HH, Zhang $\mathrm{Y}$ et al. Autoantibodies against type I IFNs in patients with life-threatening COVID-19. Science. 2020;370(6515). doi:https://doi.org/10.1126/science.abd4585.

91. Groves M. Pharmaceutical Biotechnology. 2nd ed. New York: Taylor \& Francis Group; 2005.

92. McNab F, Mayer-Barber K, Sher A, Wack A, O'Garra A. Type I interferons in infectious disease. Nat Rev Immunol. 2015;15(2):87-103. https://doi.org/10.1038/nri3787. 
93. Platanias LC. Mechanisms of type-I- and type-II-interferonmediated signalling. Nat Rev Immunol. 2005;5(5):375-86. https://doi.org/10.1038/nri1604.

94. Gonzalez-Navajas JM, Lee J, David M, Raz E. Immunomodulatory functions of type I interferons. Nat Rev Immunol. 2012;12(2):125-35. https://doi.org/10.1038/nri3133.

95. Bergman SJ, Ferguson MC, Santanello C. Interferons as therapeutic agents for infectious diseases. Infect Dis Clin North Am. 2011;25(4):819-34. https://doi.org/10.1016/j.idc.2011.07.008.

96. Prokunina-Olsson L, Alphonse N, Dickenson RE, Durbin JE, Glenn JS, Hartmann R et al. COVID-19 and emerging viral infections: the case for interferon lambda. J Exp Med. 2020;217(5). https://doi.org/10.1084/jem.20200653

97. Sánchez A, Tobío Ma, González L, Fabra A, Alonso MaJ. Biodegradable micro- and nanoparticles as long-term delivery vehicles for interferon-alpha. Eur J Pharm Sci. 2003;18(3-4):221-9. https://doi.org/10.1016/s0928-0987(03)00019-8.

98. Karau C, Petszulat M, Schmidt PC. Preparation and stability of interferon- $\alpha$-containing liposomes. Int J Pharmaceut. 1996;128(1-2):89-98. https://doi.org/10.1016/0378-5173(95) 04227-x.

99. Eppstein DA, Marsh YV, van der Pas M, Felgner PL, Schreiber $\mathrm{AB}$. Biological activity of liposome-encapsulated murine interferon gamma is mediated by a cell membrane receptor. Proc Natl Acad Sci USA. 1985;82(11):3688-92. https://doi.org/10.1073/ pnas.82.11.3688.

100. Saravolac EG, Kournikakis B, Gorton L, Wong JP. Effect of liposome-encapsulation on immunomodulating and antiviral activities of interferon-gamma 1. Antiviral Res. 1996;29(23):199-207. https://doi.org/10.1016/0166-3542(95)00832-2.

101. Ishikawa H, Barber GN. STING is an endoplasmic reticulum adaptor that facilitates innate immune signalling. Nature. 2008;455(7213):674-8. https://doi.org/10.1038/nature07317.

102. Chattopadhyay S, Hu CJ. Nanomedicinal delivery of stimulator of interferon genes agonists: recent advances in virus vaccination. Nanomedicine (Lond). 2020. https://doi.org/10.2217/ nnm-2020-0269.

103. Chattopadhyay S, Liu YH, Fang ZS, Lin CL, Lin JC, Yao BY, et al. Synthetic immunogenic cell death mediated by intracellular delivery of STING agonist nanoshells enhances anticancer chemo-immunotherapy. Nano Lett. 2020;20(4):2246-56. https:// doi.org/10.1021/acs.nanolett.9b04094.

104. Lin LC, Huang CY, Yao BY, Lin JC, Agrawal A, Algaissi A, et al. Viromimetic sting agonist-loaded hollow polymeric nanoparticles for safe and effective vaccination against Middle East respiratory syndrome coronavirus. Adv Funct Mater. 2019;29(28):1807616. https://doi.org/10.1002/adfm.201807616.

105. Wang J, Li P, Yu Y, Fu Y, Jiang H, Lu M et al. Pulmonary surfactant-biomimetic nanoparticles potentiate heterosubtypic influenza immunity. Science. 2020;367(6480). https://doi.org/ 10.1126/science.aau0810

106. Shae D, Becker KW, Christov P, Yun DS, Lytton-Jean AKR, Sevimli S, et al. Endosomolytic polymersomes increase the activity of cyclic dinucleotide STING agonists to enhance cancer immunotherapy. Nat Nanotechnol. 2019;14(3):269-78. https:// doi.org/10.1038/s41565-018-0342-5.

107. Luo M, Wang H, Wang Z, Cai H, Lu Z, Li Y, et al. A STINGactivating nanovaccine for cancer immunotherapy. Nat Nanotechnol. 2017;12(7):648-54. https://doi.org/10.1038/nnano.2017.52.

108. Aroh C, Wang Z, Dobbs N, Luo M, Chen Z, Gao J, et al. Innate immune activation by cGMP-AMP nanoparticles leads to potent and long-acting antiretroviral response against HIV1. J Immunol. 2017;199(11):3840-8. https://doi.org/10.4049 /jimmunol.1700972.

109. Lin SY, Yao BY, Hu CJ, Chen HW. Induction of robust immune responses by $\mathrm{CpG}-\mathrm{ODN}$-loaded hollow polymeric nanoparticles for antiviral and vaccine applications in chickens. Int J Nanomedicine. 2020;15:3303-18. https://doi.org/10.2147/IJN. S241492.

110. Yan Z, Li H, Chen F. Novel influenza A (H6N1) virus that infected a person in Taiwan. Iran J Public Health. 2014;43(11):1582-4.

111. Zhou D, Dejnirattisai W, Supasa P, Liu C, Mentzer AJ, Ginn $\mathrm{HM}$ et al. Evidence of escape of SARS-CoV-2 variant B.1.351 from natural and vaccine induced sera. Cell. 2021. https://doi. org/10.1016/j.cell.2021.02.037

112. Li Q, Nie J, Wu J, Zhang L, Ding R, Wang H et al. No higher infectivity but immune escape of SARS-CoV-2 501Y.V2 variants. Cell. 2021. https://doi.org/10.1016/j.cell.2021.02.042

113. Bricarello DA, Patel MA, Parikh AN. Inhibiting host-pathogen interactions using membrane-based nanostructures. Trends Biotechnol. 2012;30(6):323-30. https://doi.org/10.1016/j. tibtech.2012.03.002.

114. Hu CM, Zhang L, Aryal S, Cheung C, Fang RH, Zhang L. Erythrocyte membrane-camouflaged polymeric nanoparticles as a biomimetic delivery platform. Proc Natl Acad Sci U S A. 2011;108(27):10980-5. https://doi.org/10.1073/pnas. 1106634108

115. Hu CM, Fang RH, Luk BT, Zhang L. Nanoparticle-detained toxins for safe and effective vaccination. Nat Nanotechnol. 2013;8(12):9338. https://doi.org/10.1038/nnano.2013.254.

116. Gao W, Hu CM, Fang RH, Luk BT, Su J, Zhang L. Surface functionalization of gold nanoparticles with red blood cell membranes. Adv Mater. 2013;25(26):3549-53. https://doi.org/10.1002/adma. 201300638.

117. Luk BT, Hu CM, Fang RH, Dehaini D, Carpenter C, Gao $\mathrm{W}$, et al. Interfacial interactions between natural RBC membranes and synthetic polymeric nanoparticles. Nanoscale. 2014;6(5):2730-7. https://doi.org/10.1039/c3nr06371b.

118. Rao L, Bu LL, Xu JH, Cai B, Yu GT, Yu X, et al. Red blood cell membrane as a biomimetic nanocoating for prolonged circulation time and reduced accelerated blood clearance. Small. 2015;11(46):6225-36. https://doi.org/10.1002/smll. 201502388.

119. Hu Q, Sun W, Qian C, Wang C, Bomba HN, Gu Z. Anticancer platelet-mimicking nanovehicles. Adv Mater. 2015;27(44):7043-50. https://doi.org/10.1002/adma. 201503323.

120. Hu CM, Fang RH, Wang KC, Luk BT, Thamphiwatana S, Dehaini D, et al. Nanoparticle biointerfacing by platelet membrane cloaking. Nature. 2015;526(7571):118-21. https://doi.org/ 10.1038/nature15373.

121. Rao L, Wang W, Meng QF, Tian M, Cai B, Wang Y, et al. A Biomimetic nanodecoy traps Zika virus to prevent viral infection and fetal microcephaly development. Nano Lett. 2019;19(4):221522. https://doi.org/10.1021/acs.nanolett.8b03913.

122. Zhang P, Chen Y, Zeng Y, Shen C, Li R, Guo Z, et al. Virusmimetic nanovesicles as a versatile antigen-delivery system. Proc Natl Acad Sci U S A. 2015;112(45):E6129-38. https://doi.org/ 10.1073/pnas.1505799112.

123. Gamblin SJ, Skehel JJ. Influenza hemagglutinin and neuraminidase membrane glycoproteins. J Biol Chem. 2010;285(37):28403-9. https://doi.org/10.1074/jbc.R110. 129809.

124. Papp I, Sieben C, Ludwig K, Roskamp M, Bottcher C, Schlecht $\mathrm{S}$, et al. Inhibition of influenza virus infection by multivalent sialic-acid-functionalized gold nanoparticles. Small. 2010;6(24):2900-6. https://doi.org/10.1002/smll.201001349.

125. Zeng H, Goldsmith CS, Maines TR, Belser JA, Gustin KM, Pekosz A, et al. Tropism and infectivity of influenza virus, including highly pathogenic avian $\mathrm{H} 5 \mathrm{~N} 1$ virus, in ferret 
tracheal differentiated primary epithelial cell cultures. J Virol. 2013;87(5):2597-607. https://doi.org/10.1128/JVI.02885-12.

126. Kwon SJ, Na DH, Kwak JH, Douaisi M, Zhang F, Park EJ, et al. Nanostructured glycan architecture is important in the inhibition of influenza A virus infection. Nat Nanotechnol. 2017;12(1):4854. https://doi.org/10.1038/nnano.2016.181.

127. Chen HW, Fang ZS, Chen YT, Chen YI, Yao BY, Cheng JY, et al. Targeting and enrichment of viral pathogen by cell membrane cloaked magnetic nanoparticles for enhanced detection. ACS Appl Mater Interfaces. 2017;9(46):39953-61. https://doi. org/10.1021/acsami.7b09931.

128. Nie C, Stadtmuller M, Yang H, Xia Y, Wolff T, Cheng C, et al. Spiky nanostructures with geometry-matching topography for virus inhibition. Nano Lett. 2020;20(7):5367-75. https://doi.org/ 10.1021/acs.nanolett.0c01723.

129. Nie C, Stadtmüller M, Parshad B, Wallert M, Ahmadi V, Kerkhoff $\mathrm{Y}$ et al. Heteromultivalent topology-matched nanostructures as potent and broad-spectrum influenza A virus inhibitors. Science Advances. 2021;7(1). https://doi.org/10.1126/sciadv.abd3803

130. Trkola A, Dragic T, Arthos J, Binley JM, Olson WC, Allaway GP, et al. CD4-dependent, antibody-sensitive interactions between HIV-1 and its co-receptor CCR-5. Nature. 1996;384(6605):1847. https://doi.org/10.1038/384184a0.

131. Bronshtein T, Toledano N, Danino D, Pollack S, Machluf M. Cell derived liposomes expressing CCR5 as a new targeted drug-delivery system for HIV infected cells. J Control Release. 2011;151(2):139-48. https://doi.org/10.1016/j.jconrel.2011.02. 023.

132. de Carvalho JV, de Castro RO, da Silva EZ, Silveira PP, da Silva-Januario ME, Arruda E, et al. Nef neutralizes the ability of exosomes from CD4+ T cells to act as decoys during HIV-1 infection. PLoS ONE. 2014;9(11):e113691. https://doi.org/10. 1371/journal.pone.0113691.

133. Wei X, Zhang G, Ran D, Krishnan N, Fang RH, Gao W, et al. T-cell-mimicking nanoparticles can neutralize HIV infectivity. Adv Mater. 2018;30(45):e1802233. https://doi.org/10.1002/adma. 201802233.

134. Zhang G, Campbell GR, Zhang Q, Maule E, Hanna J, Gao W et al. CD4(+) T cell-mimicking nanoparticles broadly neutralize HIV-1 and suppress viral replication through autophagy. mBio. 2020;11(5). https://doi.org/10.1128/mBio.00903-20.

135. Mlakar J, Korva M, Tul N, Popovic M, Poljsak-Prijatelj M, Mraz $\mathrm{J}$, et al. Zika virus associated with microcephaly. N Engl J Med. 2016;374(10):951-8. https://doi.org/10.1056/NEJMoa1600651.

136. Petersen LR, Jamieson DJ, Powers AM, Honein MA. Zika Virus. N Engl J Med. 2016;374(16):1552-63. https://doi.org/10.1056/ NEJMra1602113.

137. Lee I, Bos S, Li G, Wang S, Gadea G, Despres P et al. Probing molecular insights into Zika virus(-)host interactions. Viruses. 2018;10(5). https://doi.org/10.3390/v10050233
138. Zhang Q, Honko A, Zhou J, Gong H, Downs SN, Vasquez JH, et al. Cellular nanosponges inhibit SARS-CoV-2 infectivity. Nano Lett. 2020;20(7):5570-4. https://doi.org/10.1021/acs. nanolett.0c02278.

139. Rao L, Xia S, Xu W, Tian R, Yu G, Gu C, et al. Decoy nanoparticles protect against COVID-19 by concurrently adsorbing viruses and inflammatory cytokines. Proc Natl Acad Sci U S A. 2020;117(44):27141-7. https://doi.org/10.1073/pnas. 2014352117

140. Liu X, Yuan L, Zhang L, Mu Y, Li X, Liu C, et al. Bioinspired artificial nanodecoys for hepatitis B virus. Angew Chem Int Ed Engl. 2018;57(38):12499-503. https://doi.org/10.1002/anie.201807212.

141. Thamphiwatana S, Angsantikul P, Escajadillo T, Zhang Q, Olson J, Luk BT, et al. Macrophage-like nanoparticles concurrently absorbing endotoxins and proinflammatory cytokines for sepsis management. Proc Natl Acad Sci USA. 2017;114(43):11488-93. https:// doi.org/10.1073/pnas.1714267114.

142. Kalil AC, Patterson TF, Mehta AK, Tomashek KM, Wolfe CR, Ghazaryan V, et al. Baricitinib plus remdesivir for hospitalized adults with Covid-19. New Engl J Med. 2021;384(9):795-807. https://doi.org/10.1056/NEJMoa2031994.

143. Wu J, Wang H, Li B. Structure-aided ACEI-capped remdesivirloaded novel PLGA nanoparticles: toward a computational simulation design for anti-SARS-CoV-2 therapy. Phys Chem Chem Phys. 2020;22(48):28434-9. https://doi.org/10.1039/ d0cp04389c.

144. Ansari MJ, Alshahrani SM. Nano-encapsulation and characterization of baricitinib using poly-lactic-glycolic acid co-polymer. Saudi Pharmaceutical Journal. 2019;27(4):491-501. https://doi. org/10.1016/j.jsps.2019.01.012.

145. Shi J, Kantoff PW, Wooster R, Farokhzad OC. Cancer nanomedicine: progress, challenges and opportunities. Nat Rev Cancer. 2017;17(1):20-37. https://doi.org/10.1038/nrc.2016.108.

146. DeVita VT Jr. The 'war on cancer' and its impact. Nat Clin Pract Oncol. 2004;1(2):55. https://doi.org/10.1038/ncponc0036.

147. Ptak K, Farrell D, Panaro NJ, Grodzinski P, Barker AD. The NCI Alliance for Nanotechnology in Cancer: achievement and path forward. Wiley Interdiscip Rev Nanomed Nanobiotechnol. 2010;2(5):450-60. https://doi.org/10.1002/wnan.98.

148. He H, Liu L, Morin EE, Liu M, Schwendeman A. Survey of clinical translation of cancer nanomedicines-lessons learned from successes and failures. Acc Chem Res. 2019;52(9):2445-61. https://doi.org/10.1021/acs.accounts.9b00228.

Publisher's Note Springer Nature remains neutral with regard to jurisdictional claims in published maps and institutional affiliations. 